IZA DP No. 9053

Prenatal Stress and Low Birth Weight:

Evidence from the Super Bowl

Brian Duncan

Hani Mansour

Daniel I. Rees

May 2015 


\title{
Prenatal Stress and Low Birth Weight: Evidence from the Super Bowl
}

\author{
Brian Duncan \\ University of Colorado Denver \\ Hani Mansour \\ University of Colorado Denver and IZA \\ Daniel I. Rees \\ University of Colorado Denver and IZA
}

Discussion Paper No. 9053
May 2015

IZA

P.O. Box 7240

53072 Bonn

Germany

Phone: +49-228-3894-0

Fax: +49-228-3894-180

E-mail: iza@iza.org

\begin{abstract}
Any opinions expressed here are those of the author(s) and not those of IZA. Research published in this series may include views on policy, but the institute itself takes no institutional policy positions. The IZA research network is committed to the IZA Guiding Principles of Research Integrity.

The Institute for the Study of Labor (IZA) in Bonn is a local and virtual international research center and a place of communication between science, politics and business. IZA is an independent nonprofit organization supported by Deutsche Post Foundation. The center is associated with the University of Bonn and offers a stimulating research environment through its international network, workshops and conferences, data service, project support, research visits and doctoral program. IZA engages in (i) original and internationally competitive research in all fields of labor economics, (ii) development of policy concepts, and (iii) dissemination of research results and concepts to the interested public.
\end{abstract}

IZA Discussion Papers often represent preliminary work and are circulated to encourage discussion. Citation of such a paper should account for its provisional character. A revised version may be available directly from the author. 
IZA Discussion Paper No. 9053

May 2015

\section{ABSTRACT \\ Prenatal Stress and Low Birth Weight: Evidence from the Super Bowl}

Studies have estimated the relationship between psychological stress and birth weight by exploiting natural disasters and terrorist attacks, both of which could affect fetal health through other channels. Using data from the National Vital Statistics System for the period 1969-2004, we estimate the effect of prenatal exposure to the Super Bowl on low birth weight. Although major sporting events elicit intense emotions, they do not threaten viewers with direct physical harm or limit access to prenatal care. We find that Super Bowl exposure is associated with a small, but precisely estimated, increase in the probability of low birth weight.

JEL Classification: I12, J13

Keywords: $\quad$ low birth weight, Super Bowl, prenatal stress, tobacco use

Corresponding author:

Hani Mansour

Department of Economics

University of Colorado Denver

Campus Box 181

Denver, CO 80217

USA

E-mail: hani.mansour@ucdenver.edu

\footnotetext{
${ }^{*}$ We are grateful to Gordon Dahl for extensive comments on earlier versions of this paper. We also thank Janet Currie, Joseph Price, Prashant Bharadwaj, Ryan Brown, and seminar participants at Princeton University, the University of California at Riverside, and at the 2012 Southern Economic Association Meetings for helpful comments.
} 


\section{INTRODUCTION}

Prenatal shocks to fetal health can have long-lasting economic consequences (Almond and Currie 2011) and can take many forms. For instance, previous researchers have examined the effects of poor nutrition (Lumey 1997; Almond and Mazumder 2011), pollution (Currie et al. 2011; Currie and Reed 2011) and infection (Kelly 2011; Currie and Schwandtz 2013; Schwandt 2014) on birth outcomes. There is also reason to believe that prenatal shocks can be psychological in nature (Aizer et al. 2012), but identifying the effects of stress experienced during pregnancy has proven to be difficult (Currie and Rossin-Slater 2013).

To date, the strongest evidence that psychological stress is causally related to birth weight comes from quasi-experimental studies that exploit catastrophic natural events such as earthquakes (Glyn et al. 2001; Torche 2011), unexpected acts of extreme violence (Eskenazi et al. 2007; Camacho 2008; Mansour and Rees 2012) or tragic events such as the loss of a parent (Black et al. 2014; Persson and Rossin-Slater 2014). However, as noted by Black et al. (2014), even these quasi-experimental studies have struggled to clearly distinguish the effect of psychological stress from other more tangible consequences of the event itself. For instance, natural disasters could potentially limit access to prenatal care or reduce the availability of nutrient-rich food, while the death of a parent could affect the financial resources available to a family.

The focus of the current study is on prenatal exposure to an event that takes place every year, the Super Bowl. The Super Bowl is the championship game of the National Football League (NFL); it draws tens of millions of television viewers and generates billions of dollars in 
revenue. ${ }^{1}$ Unlike earthquakes and terrorist attacks, the Super Bowl does not prevent women from seeking prenatal care, nor does it threaten its viewers with direct physical harm or loss of livelihood. To our knowledge, no previous study has examined the effect of intrauterine exposure to a sporting event, although major sporting events clearly elicit intense emotions and even violent reactions (White et al. 1992; Kloner et al. 2009; Rees and Schnepel 2009; Card and Dahl 2011).

Drawing on publicly available data from the National Vital Statistics System (NVSS) for the period 1969-2004, we examine children who were conceived 1-4 months before the Super Bowl by mothers who lived no further than one county away from an NFL stadium. Our identification strategy is based on the assumption that, because of various league polices designed to promote parity and the sudden-death structure of NFL playoffs, the year in which a particular team advanced to the Super Bowl can be thought of as, in effect, randomly assigned. In other words, we assume that Super Bowl exposure is orthogonal to unobservable factors influencing birth weight.

We begin our analysis by showing that observables such as mother's age, educational attainment, marital status and race are poor predictors of Super Bowl exposure, a result that is consistent with random assignment to treatment. Next, we conduct a simple event study, the results of which suggest that prenatal exposure to the Super Bowl leads, on average, to a 1.8 percent increase in the incidence of low birth weight (defined as weighing less than 2,500 grams at birth). Finally, we confirm this estimate using a standard difference-in-differences regression approach. Interestingly, exposure to a Super Bowl win is associated with a 5.1 percent increase

\footnotetext{
${ }^{1}$ The 2014 Super Bowl drew a record 112 million viewers, 46 percent of whom were women (Block 2015). In comparison, the 2014 Academy Awards drew 43 million viewers (Hinckley 2014). Recent Super Bowls have generated over 100 million dollars in merchandise sales and over 300 million dollars in advertising revenue (Muret 2014; Erb 2015).
} 
in probability of having a low birth-weight child, while the estimated effect of being exposed to a Super Bowl loss is much smaller and statistically insignificant. Upset wins, which can be thought of as exogenously generated positive emotional cues (Card and Dahl 2011), are associated with larger increases in the probability of having a low birth weight child than are predicted wins. $^{2}$

As noted by Eskenazi et al. (2007, p. 3014) and others, the psychological stress from exposure to an unexpected dramatic event could, in theory, provoke "maladaptive coping behaviors", ultimately impacting the health of the fetus. For example, exposure to the Super Bowl could affect substance use or trigger intimate partner violence. Although we do not have data on the use of illegal substances or intimate partner violence, we are able to explore a subset of potential behavioral responses to Super Bowl exposure, including smoking. Our results provide strong evidence that psychological stress is, at a minimum, the first step along the causal pathway.

\section{BACKGROUND}

\subsection{Prenatal stress and birth weight}

Psychological stress experienced during pregnancy is associated with low birth weight (Beydoun and Saftlas 2008). Possible biological mechanisms include increased levels of Corticotropin-Releasing Hormone and decreased uterine blood flow (Mulder et al. 2002;

Wadhwa et al. 2004; de Weerth and Buitelaar 2005), although this association could simply reflect the influence of confounding factors (Almond and Currie 2011).

\footnotetext{
${ }^{2}$ We do not focus on regular-season games because fertility decisions could be a function of team performance, which is predictable. Moreover, the Super Bowl arguably affects a larger share of the population as compared to regular-season games.
} 
Studies seeking to establish a causal link between psychological stress and birth weight are often based on dramatic, unexpected events. For instance, using vital statistics records from New York, Eskenazi et al. (2007) found an increased risk of very low birth weight (i.e., less than 1,500 grams) among children born 33 through 36 weeks after the 2001 attack on World Trade Center. Glyn et al. (2001) found that first-trimester exposure to an earthquake that struck Northridge, California in 1994 was associated with a reduction in gestation duration of approximately 10 days, and Torche (2011) found that first-trimester exposure to an earthquake that struck northern Chile in 2005 was associated with fewer weeks of gestation and an increased risk of low birth weight. ${ }^{3}$

Of course, psychological stress is caused by a wide variety of events and circumstances, some of which are quite mundane. There is evidence that arguing with a spouse leads to increased levels of cortisol, a hormone released by the hypothalamic-pituitaryadrenal axis in response to stress (Kiecolt-Glaser et al. 1996; Heffner et al. 2004). There is also evidence that speaking in public (Kemmer et al. 1986; Kirschbaum et al. 1995), being exposed to a loud noise or music (Testa et al. 1994; Gerra et al. 1998), or even watching a sporting event on television (van der Meij et al. 2012) can increase cortisol levels.

Studies based on dramatic, unexpected events provide support for the hypothesis that psychological stress is causally related to birth weight, but most pregnant women are at greater risk of having an argument with their spouse or watching a sporting event on television than

\footnotetext{
${ }^{3}$ Additional studies of the relationship between a plausibly exogenous psychological stressor and birth weight include: Smits et al. (2006), Camacho (2008), Khashan et al. (2008), Mansour and Rees (2012), Black et al. (2014), Persson and Rossin-Slater (2014), and Brown (2015). See Mulder et al. (2002) and Beydoun and Saftlas (2008) for reviews of the experimental literature on this topic. Schneider et al. (1999) subjected pregnant rhesus monkeys to stress by administering noise bursts. These authors found that early-pregnancy exposure to noise bursts led to significantly lower birth weight, but noise bursts administered later in the pregnancy did not.
} 
experiencing an earthquake. As noted by Almond and Currie (2011, p. 164), commonplace

intrauterine shocks are arguably more policy relevant than rarer events:

Economists have utilized the power of large-sample datasets to detect effects of relatively mild fetal insults. This extension is key as exposure to relatively mild pathogens is common. Hence, estimates of the effects of mild exposures may be more relevant to policy than estimates of the effects of disasters.

\subsection{Sporting events as prenatal stressors}

The Super Bowl does not threaten its viewers with direct physical harm, limit access to prenatal care, or prevent mothers from access to nutrient-rich food. There is, however, evidence from a variety of sources that major sporting events can produce intense emotions, especially when their outcome is unexpected.

For instance, Rees and Schnepel (2009) examined the relationship between Division I-A college football games and reported crime. These authors documented sharp increases in assaults and vandalism on game days. Although college football games often attract a temporary influx of people from outside the host community, Rees and Schnepel (2009) found that upsets led to more assaults and vandalism than non-upsets, suggesting that fans were reacting to the outcome of the game.

Card and Dahl (2011) examined the relationship between domestic violence and the outcomes of regular-season NFL games. They argued that, conditional on the Las Vegas point spread, these outcomes could be thought of as exogenously generated emotional cues. ${ }^{4}$ Card and Dahl found that upset losses were associated with a 10 percent increase in the number of police reports of male-on-female intimate partner violence (IPV), while the estimated relationship

\footnotetext{
${ }^{4}$ In order to ensure that the betting market clears, Las Vegas bookmakers produce "point-spreads" before each regular-season and post-season NFL game. Research by Gandar et al. (1988), and Card and Dahl (2011) provides evidence that the closing point spread is a strong, unbiased predictor of game outcome.
} 
between upset wins and male-on-female IPV was much smaller and statistically insignificant at conventional levels.

Kloner et al. (2009) analyzed Los Angeles County death records from January and February for the period 1980-1988. These authors found a spike in "cardiac events" immediately after the 1980 Super Bowl, when the Pittsburgh Steelers staged a fourth-quarter comeback to beat the Los Angeles Rams. Four years later when the Los Angeles Raiders cruised to an easy victory over the Washington Redskins (the final score was 38 to 9), there was no detectible increase in heart attacks in the Los Angeles area and the overall death rate actually fell slightly. ${ }^{5}$ Kloner et al. (2009) concluded that, "the emotional stress of loss by a local sports team in a highly publicized rivalry such as the Super Bowl can serve as a trigger of cardiovascular death" (p. 1649).

\section{THE DATA}

The registration of births, deaths and other vital events is done at the state level, but the National Center for Health Statistics (NCHS) is responsible for collecting and disseminating vital statistics data, which are made available through the National Vital Statistics System (NVSS). Our empirical analysis draws on NVSS data for the period 1969-2004, the final year in which geographic identifiers were publicly available. The sample is composed of $12,179,714$ children, all of whom were conceived approximately 1-4 months before the Super Bowl by mothers living in what we label an NFL "fan base area." NFL fan base area is assigned using the mother's county of residence. In 1969 there were 10 AFL (American Football League) and 16 NFL football teams. By 2004, the two leagues had merged, and the NFL included 32 teams, some of

\footnotetext{
${ }^{5}$ A related study examined cardiovascular events among residents of the greater Munich area during the 2006 Federation Internationale de Football Association World Cup (Wilbert-Lampen et al. 2008). The authors found that when the German team played, cardiac emergencies increased sharply among both men and women.
} 
which had changed stadiums during the previous 35 years. If an NFL stadium was located in a county at any time during the period 1969-2004, then that county and its neighboring counties constitute one of 32 unique NFL fan base areas in the analyses below. ${ }^{6}$

Month of conception was assigned using gestation duration (in weeks) and month of birth. $^{7}$ In order to focus on exposure to the Super Bowl during early pregnancy, we begin by restricting the sample to children whose likely month of conception was October, November, and December, although below (in section 4.7) we consider exposure in the second trimester. ${ }^{8}$ With only a handful of exceptions, previous studies in this literature have concluded that psychological stress experienced after the first trimester is unrelated to birth outcomes. ${ }^{9}$ The sample is further restricted to children with a gestation length of 25 weeks or greater. ${ }^{10}$ Obstetricians and gynecologists consider a fetus potentially viable at 24 weeks (Morgan et al. 2008), but the

\footnotetext{
${ }^{6}$ Several of the 32 NFL fan base areas did not have football teams every year during the period under study. However, all children born between 1969 and 2004 to mothers living in these fan base areas were included in the analysis.

${ }^{7}$ Between 1969 and 1988, the public-use NVSS data included an exact date of birth. However, because of changing confidentiality standards, only month of birth was provided after 1988. We assigned date of birth to the $15^{\text {th }}$ of the month to children whose birth date was missing and, by subtracting gestation duration (in weeks), determine their likely month of conception. We experimented with assigning date of birth to the first day of the month. Our results were not sensitive to this alternative method of assigning date of birth. Likewise, we experimented with assigning date of birth to last day of the month. Again, our results were not sensitive to this alternative method of assigning date of birth.

${ }^{8}$ The Super Bowl took place in January until 2002, when it was played on February 3; in 2003, it was played on January 26, and in 2004 it was played on February 1.

${ }^{9}$ The exceptions are Smits (2006), Black et al. (2014) and Persson and Rossin-Slater (2014). Smits et al. (2006) examined a sample of Dutch children who were in utero when the September $11^{\text {th }}$ attack occurred. These authors found that second- and third-trimester exposure to the attack was associated with a reduction in birth weight. Black et al. (2014) and Persson and Rossin-Slater (2014) examined prenatal exposure to the death of a close relative. Black et al. (2014) focused on mothers who experienced the death of a parent, and found coefficient sizes that were "relatively constant across trimesters" (p. 20). Persson and Rossin-Slater (2014) found effects that were "similar across the trimesters," but noted that "the impacts on birth weight and head circumference seem to be largest when exposure is in the first trimester" (p. 18). See also Khashan et al. (2008).

${ }^{10}$ This restriction reduced the sample by 37,802 births (or by 0.31 percent). Including children with a gestation length shorter than 25 weeks does not appreciably alter the results reported below.
} 
survival rate is less than 50 percent (Kaemph et al. 2006). The survival rate at 25 weeks of gestation is approximately 60 percent (Kaemph et al. 2006).

The mean birth weight in our sample is 3,314 grams (Table 1). ${ }^{11}$ Seven percent of the children weighted less than 2,500 grams at birth, the standard cut-off for low birth weight in the medical literature. ${ }^{12}$ Mean gestation duration in our sample is 39.0 weeks, as compared to 38.7 weeks among singletons born to U.S. mothers in 2005 (Centers for Disease Control and Prevention 2008). ${ }^{13}$

\section{PRENATAL EXPOSURE TO SUPER BOWL AND LOW BIRTH WEIGHT}

\subsection{Identification strategy}

Appendix Table 1 provides information on the 36 Super Bowls played during the period 1969-2004. During this period, 23 fan base areas were exposed to a Super Bowl at least once, and several were exposed more than once. Obviously, NFL teams are not randomly assigned to communities, but our analyses rely on within-community variation over time, in effect using each fan base area as its own control.

The NFL has adopted a number of policies designed to promote competitive balance, including ordering the draft (the team with the worst regular-season record picks first), free

\footnotetext{
${ }^{11}$ In 2005, the mean birth weight of singletons born in the United States was 3,389 grams (Donahue et al. 2010). Appendix Table 2 presents descriptive statistics by Super Bowl exposure.

${ }^{12}$ Using vital statistics records from 2006, Martin et al. (2008) found that 8.3 percent of infants born in the United States weighed less than 2,500 grams. Low birth weight is strong predictor of educational attainment and earnings as an adult, although there is some question as to whether it is causally related to these outcomes. Black et al. (2007) and Royer (2009) provide estimates of the relationship between birth weight and outcomes of interest to economists using twins data.

${ }^{13}$ According to the Centers for Disease Control and Prevention (2008), the mean gestation duration for twins was 35.2 weeks in 2005; among triplets it was 31.9 weeks. In the NVSS, gestation duration is based on the interval between the first day of the mother's last normal menstrual period (LMP) and the date of birth or a "clinical estimate of gestation."
} 
agency, and the salary cap (Young 2014; Bien 2015). ${ }^{14}$ These policies, combined with the sudden-death structure of the NFL playoffs, make it exceedingly difficult to predict which two teams will advance to the Super Bowl in any given year. The validity of our identification strategy rests on the premise that, for any given fan base area, the year in which their team advances to the Super Bowl is as good as randomly assigned. In this context, as-good-as-random assignment means that the year in which a team advances to the Super Bowl is independent of unobservable factors influencing birth weight. While this assumption is fundamentally untestable, we provide strong empirical evidence supporting its validity.

Several previous studies in this literature have attempted to address complications due to geographical sorting and selective fertility. ${ }^{15}$ Because the Super Bowl does not disrupt city services or cause damage to infrastructure, geographical sorting is unlikely. Fertility decisions could, however, be influenced by a team's regular season record and playoff performance, potentially changing the composition of pregnant women exposed to the Super Bowl. In an effort to address this concern, we begin by examining the relationship between Super Bowl exposure and observable features of the mother and birth. Specifically, we consider the following linear probability model:

$$
\text { SuperBowl }_{\text {iat }}=\alpha+\boldsymbol{X}_{\text {iat }} \boldsymbol{\delta}+v_{a}+w_{t}+\theta_{a} t+\varepsilon_{\text {iat }},
$$

where SuperBowliat is an indicator for whether child $i$ born in fan base area $a$ and year $t$ was exposed to the Super Bowl, year fixed effects are represented by $w_{t}$, area fixed effects are

\footnotetext{
${ }^{14}$ The NFL's commitment to league parity is embodied in its motto "Any given Sunday," which alludes to the fact that even the worst team in the league has a chance of beating the best team.

${ }^{15}$ For example, an earthquake or hurricane might cause some pregnant women to move out of the affected area, creating the potential for endogenous sorting. Currie and Rossin-Slater (2013, p. 494) accounted for geographical sorting by using "the hypothetical exposure the mother would have experienced during each trimester of pregnancy as if she had never moved" to instrument for exposure. Black et al. (2014) accounted for selective fertility and reverse causality by comparing mothers who experienced a death of a parent during pregnancy to mothers who experienced the death of a parent immediately before or after pregnancy.
} 
represented by $v_{a}$, and area-specific linear time trends are represented by $\theta_{a} t$. The vector $\boldsymbol{X}_{\text {iat }}$ includes indicators for month of conception, sex of the child, hospital birth, multiple birth, mother's first birth, father indicated on birth certificate, mother's race, ethnicity, educational attainment, age, and marital status. If Super Bowl years are, in effect, randomly assigned to mothers, then these observable features of the mother and birth should be poor predictors of Super Bowl exposure. Estimates of (1), presented in Table 2, suggest that this is the case. Estimates of the coefficients represented by $\boldsymbol{\delta}$ are, without exception, insignificant. Moreover, the partial R-squared for the observables is 0.0004 , indicating that together they explain less than 0.1 percent of the variation in SuperBowl. Consistent with this result, controlling for observable features of the mother and birth has almost no impact on our difference-in-differences estimates presented below.

It is difficult to imagine why Super Bowl exposure would be essentially uncorrelated with observables such as mother's age and race, but correlated with the unobserved determinants of birth weight. Nevertheless, we provide two corroborating pieces of evidence for exogeneity below. First, we test whether mothers were more likely to have a low birth weight child the year before being exposed to the Super Bowl. The estimated coefficient of the Super Bowl lead is small and statistically insignificant, suggesting that our results are not being driven by difficultto-observe trends in the determinants of birth weight. Second, we use the pre-game Las Vegas point spread to identify upset wins and losses, which are inherently difficult to predict (Gandar et al. 1988; Card and Dahl 2011). We find that exposure to an upset win is associated with a substantial increase in the probability of low birth weight, while exposure to a predicted win is associated with a significantly smaller increase in this probability; exposure to other Super Bowl outcomes (e.g., a predicted loss) is essentially unrelated to birth weight. 


\subsection{Event study of Super Bowl runs}

If the year in which an NFL team advances to the playoffs is as good as randomly assigned, then identifying the treatment effect of prenatal exposure to the Super Bowl on birth outcomes can proceed much as it would in a randomized control trial. We begin by conducting a simple event study that compares birth outcomes in Super Bowl years with birth outcomes in the years immediately before and after a Super Bowl appearance. Although we also examine birth weight in grams, our focus is on low birth weight. As noted by Currie and Walker (2011, p. 71), most studies of infant health have focused on the lower tail of the birth weight distribution by using a 2,500 gram cutoff for low birth weight.

Our event study is complicated by the fact that teams can make back-to-back Super Bowl appearances. To account for this, we consider Super Bowl "runs", defined as the year in which a team advanced to the Super Bowl or all of the years in series of back-to-back Super Bowl appearances with no more than a one-year gap. Using this definition, there were 44 distinct Super Bowl runs during the period under study. ${ }^{16}$

Figure 1 shows the percentage of children whose birth weight was below the 2,500 gram cutoff in a fan base area the year before, the year (or years) during, and the year following each of these 44 Super Bowl runs. An example of a simple one-year Super Bowl run is provided by the Baltimore Ravens, who played in the 2001 Super Bowl. Baltimore's previous Super Bowl appearance was in 1971, and the team did not return to the Super Bowl until 2013. The Figure 1 panel labeled BAL (Run \#1) shows that 9.69 percent of children born in the Baltimore fan base area during the 2001 Super Bowl year were below the 2,500 gram cutoff, as compared to 8.94

\footnotetext{
${ }^{16}$ Super Bowl runs that began before 1969 (the Baltimore Colts and the New York Jets) or concluded after 2004 (Carolina Panthers and New England Patriots) are excluded from this event study because the NVSS data for the year before or after the super bowl run are not available.
} 
percent the previous year and 9.67 percent the following year.

An example of a more complicated multiple-year Super Bowl run is provided by the Denver Broncos, who played in the 1987, 1988 and 1990 Super Bowls. The Figure 1 panel labeled DEN (Run \#2) shows that 8.52 percent of children born in the Denver fan base area in the years 1987, 1988 and 1990 were below the 2,500 gram cutoff. This is identical to the percentage observed in 1986, the year before the Super Bowl run, and slightly higher than the percentage observed in 1991, the year after. Babies born in the "gap year" are not included in the analysis because 1989 was both the year before, and the year after, a Super Bowl appearance. ${ }^{17}$

It is difficult to discern a general pattern of results from the 44 panels in Figure 1, and so Figure 2A presents averages across Super Bowl runs. While the 44 Super Bowl runs were in progress, 7.85 percent of children fell below the low birth weight threshold. In comparison, 7.79 percent of children born the year before their team advanced to the super Bowl weighed less than 2,500 grams, and 7.82 percent of children born the year after their team advanced to the Super Bowl weighed less than 2,500 grams. It is important to note that these averages give equal weight to each Super Bowl run, in effect imagining each Super Bowl run as a single treatment. However, averages that give equal weight to each birth produce identical patterns. Figure $2 \mathrm{C}$ shows the corresponding averages for birth weight measured in grams, which produce a similar pattern.

An analogous set of estimates using residuals from a simple low-birth-weight regression is presented in Figure 2B. These residuals are calculated by estimating:

\footnotetext{
${ }^{17}$ We explored several alternative definitions of a Super Bowl run, including defining the Super Bowl year as simply the first year of back-to-back appearances, limiting the sample to a team's first Super Bowl appearance, and limiting the sample to include only the one-year Super Bowl runs. All of these methods yielded similar results to those presented here.
} 


$$
L B W_{i a t}=\alpha+v_{a}+w_{t}+\theta_{a} t+\varepsilon_{i a t},
$$

where $L B W_{\text {iat }}$ is an indicator of low birth weight for child $i$ born in NFL fan base area $a$ and year

t. Thus, the residuals from (2) are the deviations in low birthweight that are not explained by location, year, and area-specific linear trends, and provide a direct estimate of the Super Bowl effect.

Figure 2B shows the estimated residuals from equation (2) averaged across the 44 Super Bowl runs (again, giving equal weight to each Super Bowl run). The 44 Super Bowl runs are associated with a 0.12 percentage-point increase in the probability of low birth weight. This corresponds to a 1.5 percent increase in the incidence of low birth weight relative to the year before $(0.12 / 7.79=0.015)$. In contrast, the year before a Super Bowl run is associated with a .029 percentage-point increase in the probability of low birth weight, a result consistent with random assignment of Super Bowl exposure. ${ }^{18}$ Interestingly, the incidence of low birth weight appears to be slightly higher after Super Bowl runs. Below, we note why Super Bowl exposure might affect birth weight with a lag, but show that this particular result is not robust to using a difference-in-differences framework. ${ }^{19}$

\subsection{Baseline difference-in-differences estimates}

To explore whether prenatal exposure to the Super Bowl affects birth weight in a difference-in-difference framework, we estimate the following equation:

\footnotetext{
${ }^{18}$ Although Figure 2 displays 90-percent confidence intervals, we formally address statistical significance when we turn to the regression analysis.

${ }^{19}$ Figure $2 \mathrm{C}$ presents birth weight in grams averaged across the 44 Super Bowl runs. While these 44 runs were in progress, average birth weight was 3,298.5 grams. In comparison, average birth weight was 3,298.9 grams for children born the year before their team advanced to the super Bowl, and 3,299.4 grams for children born the year after their team advanced to the Super Bowl. Figure 2D presents residuals, averaged across the 44 Super Bowl runs, from a regression in which the dependent variable was birth weight in grams. The average Super Bowl run residual is -.2.27 grams. In comparison, the average residual is -0.32 grams for children born the year before their team advanced to the Super Bowl, and -2.87 grams for children born the year after their team advanced to the Super Bowl.
} 


$$
\begin{aligned}
\text { LBW }_{\text {iat }} & =\pi_{0}+\pi_{1} \text { SuperBowl }_{a t}+\pi_{2} \text { SuperBowl }_{a t+1}+\pi_{3} \text { SuperBowl }_{a t-1} \\
& +\pi_{4} \text { LostDivision }_{a t}+\pi_{5} \text { LostConference }_{a t}+\boldsymbol{X}_{\text {iat }} \boldsymbol{\beta}+v_{a}+w_{t}+\theta_{a} t+\varepsilon_{\text {iat }}
\end{aligned}
$$

where, as before, $L B W_{i a t}$, is an indicator variable of low birth weight. The variable SuperBowl $l_{a t}$ is equal to 1 if children living in fan base area $a$ were exposed to the Super Bowl in year $t$, and is equal to 0 otherwise. Including a one-year lead of the Super Bowl indicator, SuperBowl $l_{a t+1}$ (and a one-year lag of the Super Bowl indicator, SuperBowl $l_{a t-1}$ ), provides an additional test of our identifying assumption. If the year in which a team advances to the Super Bowl is as good as randomly assigned, then our estimate of $\pi_{2}$ should be statistically indistinguishable from zero. Because we include indicators for whether a team was eliminated in the divisional or the conference playoffs in equation (3), the coefficient of interest, $\pi_{1}$, represents the effect of exposure to the Super Bowl on the probability of having a low birth weight child as compared to not having been exposed to a Divisional Playoff game. ${ }^{20}$ The regressions include year fixed effects $\left(w_{t}\right)$, NFL fan base area fixed effects $\left(v_{a}\right)$, and, where indicated, area specific linear trends $\left(\theta_{a} t\right)$ and controls for observables $\left(\boldsymbol{X}_{\text {iat }}\right)$. Standard errors are corrected for clustering at the NFL fan base area level (Bertrand et al. 2004).

The first column of Table 3 presents ordinary least squares (OLS) estimates of a basic version of equation (3) without the controls, $\boldsymbol{X}_{\text {iat }}$, and area-specific linear trends. The coefficient of the one-year Super Bowl lead is small and statistically indistinguishable from zero. In

\footnotetext{
${ }^{20}$ Not reaching the Divisional Playoffs, losing a Divisional Playoff, losing a Conference Playoff, and going to the Super Bowl are mutually exclusive and exhaustive events. Prior to 1978, the Divisional Playoffs were the first round, and the Conference Playoffs were the second round, of the NFL playoffs. In 1978, the NFL added an additional playoff round, the "Wild Card Playoffs," and the Divisional Playoffs became the second round of the playoffs. It should be noted that the interpretation of the regression estimate, $\pi_{1}$, is slightly different than the corresponding event-study estimate. The event analysis compared the incidence of low birth weight in Super Bowl years to non-Super Bowl years, while the differences-in-differences estimate compares Super Bowl years to nonplayoff years that neither immediately precede nor follow a Super Bowl. In addition, the event analysis gave equal weight to each run, while the regression analysis gives equal weight to each birth.
} 
contrast, exposure to the Super Bowl is associated with a 0.14 percentage-point increase in the probability of having a child who weighed less than the 2,500 gram cutoff.

In the second column of Table 3 , we report an estimate of $\pi_{1}$ from a model that, like the event study, includes area-specific linear time trends. This estimate is strikingly similar to the estimate in Figure 2B: both suggest that Super Bowl exposure is associated with 0.12 percentage-point increase in the probability of having a low birth weight child.

In the third column of Table 3 , we report estimates of $\pi_{1}$ through $\pi_{5}$ controlling for observable features of the mother and birth. Consistent with the assumption that Super Bowl exposure is as good as randomly assigned, the addition of the controls leads to an improvement in precision but has almost no impact on the estimated relationship between Super Bowl exposure and low birth weight. Specifically, exposure to the Super Bowl is associated with a 0.13 percentage-point increase in the probability of having a low birth weight child, which corresponds to a 1.8 percent increase in the incidence of low birth weight $(0.13 / 7.35=0.0177)$.

This latter estimate is an order of magnitude smaller than those documented by previous researchers who exploited natural disasters and unexpected acts of violence. For instance, Torche (2011) found that first-trimester exposure to an earthquake led to an almost 40 percent increase in the incidence of low birth weight, and Eskenazi et al. (2007) found that exposure to the September 11, 2001 attack on the World Trade Center increased the odds of very low birth weight by approximately 30 percent. However, any increase in the incidence of low birth weight associated with Super Bowl exposure is best interpreted as an intent-to-treat effect (as opposed to, for instance, the effect of treatment on the treated). In 1969, the Super Bowl drew an estimated 41.7 million viewers, or 21 percent of the U.S. population; by 1986, viewership had risen to 92.6 million, or 39 percent of the U.S. population. Although viewership has risen above 
100 million in recent years, the popularity of the Super Bowl arguably peaked in the mid1980s. ${ }^{21}$

In columns (4)-(6) of Table 3, we replace our principal outcome, low birth weight, with birth weight measured in grams. Without the area-specific trends and controls, Super Bowl exposure is associated with a reduction in birth weight of 1.95 grams, although this estimate is not statistically significant at conventional levels. In column (5), we add area-specific linear trends and in column (6) we control for observables such as mother's age and race. With the area-specific trends and observables on the right-hand side, exposure to the Super Bowl is associated with a reduction in birth weight of 3.20 grams.

\subsection{Super Bowl wins vs. losses}

Super Bowl wins and losses clearly elicit distinct responses. After the Seattle Seahawks won the Super Bowl in 2014, celebrations lasted well into Monday and involved drinking, acts of vandalism, and confrontations with police (Dejohn 2014). On the Wednesday following their Super Bowl win, an estimated 700,000 Seattle Seahawks fans attended a victory parade (Lacitis 2014). In contrast, when the Seattle Seahawks lost the Super Bowl in 2015, the reaction was much more subdued. Fans were denied access to the airport when the team arrived, and the team busses avoided the parade route from the previous year in order to discourage fans from gathering downtown (Hirschhorn 2105).

In this section, we replace the Super Bowl indicator variable in equation (3) with indicators for whether the NFL team located in area $a$ won or lost the Super Bowl in year $t$ (i.e., LostSuperBowl $l_{a t}$ and WonSuperBowl $l_{a t}$ ). A priori, it is not clear whether winning or losing the

\footnotetext{
${ }^{21}$ Gorman (2009) provides viewership statistics for Super Bowls played between 1967 and 2009. Although a majority of women consider themselves to be fans, professional football is much more popular among men than among women (Jones 2001; Cunningham 2012). In 2001, 53 percent of American women reported that they were fans of professional football, as compared to 74 percent of men (Jones 2001).
} 
Super Bowl should have a larger impact on birth weight. Researchers in this area have focused almost exclusively on the relationship between negative events and birth outcomes, but there is compelling evidence that a wide variety of events and circumstances can lead to psychological stress. For instance, Brown et al. (1993) found that experimentally induced elation and sadness were both associated with increased levels of cortisol, while Hubert et al. (1993) found that cortisol levels increased when participants were exposed to an amusing film. ${ }^{22}$

To facilitate comparison, the odd-numbered columns of Table 4 reproduce estimates originally reported in Table $3 .^{23}$ Estimates of being exposed to a win versus a loss are shown in the even-numbered columns. These estimates are consistent with the hypothesis that positive emotional cues are more important than negative emotional cues, at least in this context. ${ }^{24}$ Specifically, exposure to a Super Bowl win is associated with a 0.24 percentage-point increase in the probability of low birth weight and a reduction in birth weight of 5.92 grams. In contrast, the

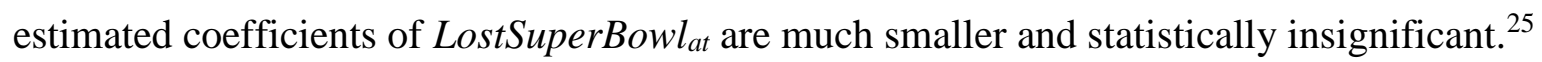

\footnotetext{
${ }^{22}$ Hubert et al. (1993) concluded that "cortisol secretion may be linked to emotional arousal, regardless of the emotional valence" (p. 265). See also López et al. (2009), van der Meij et al. (2010), van der Meij et al. (2012). López et al. (2009) found that women experienced an increase in cortisol levels when they were shown clips from popular films depicting an attractive man courting a young woman; van der Meij et al. (2010) found that men experienced an increase in cortisol levels after short social interactions with attractive women; and van de Meiji et al. (2012) found increased cortisol levels among both male and female Spanish soccer fans while watching the 2010 FIFA World Cup final between Spain and the Netherlands. Peeters et al. (2003), however, found essentially no association between "positive daily events" and cortisol levels.

${ }^{23}$ Although the coefficients of the Super Bowl leads and lags and leads are not reported in Table 4 or subsequent tables, they are consistently insignificant and their exclusion does not change the coefficients reported in below. It should be noted, however, that when the lag of Super Bowl indicator is replaced with lag of Super Bowl win and lag of Super Bowl loss, the coefficient on the lag of Super Bowl win is 0.0014 and statistically significant at the 0.05 level. Super Bowl wins could have a lagged effect on birth weight, if, for instance, they increase a team's fan base and, as a consequence, result in a general increase in prenatal exposure to sporting events. A recent Nielsen study found that, after winning the Super Bowl, "the Seahawks grew their fan base by $27 \%$ from the previous year, moving from 24th to 6th, the largest jump of any team" (Nielsen, 2015).

${ }^{24}$ It is also possible that Super Bowl wins attract a larger audience than losses and, as a consequence, treat a larger proportion of pregnant women.

${ }^{25}$ The hypothesis that the estimates of Super Bowl win and loss are equal can be rejected at the .05 level.
} 


\subsection{Heterogeneous effects}

We report estimates of the effect of Super Bowl exposure by mother's educational attainment, race, ethnicity and marital status in Panel A of Table 5. Despite the fact that NFL fans are more likely to have graduated from high school than non-fans (Jones 2001; Scarborough Research 2004), there is little evidence that Super Bowl exposure is associated with low birth weight among children whose mothers had at least four years of secondary schooling. In contrast, among children whose mothers did not complete high school, exposure to the Super Bowl is associated with a 0.19 percentage-point increase in the probability of low birth weight. One potential explanation for this pattern of results is that women who did not complete high school were at greater risk of intimate-partner violence (IPV) in the event of a loss, and therefore under more psychological stress during the game, than their counterparts with a high school or college education. ${ }^{26}$ However, winning the Super Bowl is associated with a 0.47 percentagepoint increase in the probability of low birth weight among children whose mothers did not complete high school (or a 5.1 percent increase in the incidence of low birth weight), while the estimated coefficient of LostSuperBowl is actually negative, although not statistically significant. Card and Dahl (2011) found no evidence that regular-season wins were associated with IPV.

Professional football appears to be especially popular among non-whites. According to a Gallup poll conducted in 2004,71 percent of non-whites said that they were NFL fans as compared to 62 percent of whites (Jones 2005). Panel B of Table 5 provides estimates of the relationship between Super Bowl exposure and low birth weight by the mother's race and ethnicity. When the sample is restricted to the children of white mothers, exposure to the Super Bowl is associated with a 0.07 percentage-point increase in the probability of low birth weight,

\footnotetext{
${ }^{26}$ Farmer and Tiefenthaler (2003) provide evidence that women without a high school degree are at greater risk of IPV than their counterparts with a high school or college education.
} 
and exposure to a Super Bowl win is associated with a 0.17 percentage-point increase in this probability; when the sample is restricted to the children of black mothers, the estimated effect of Super Bowl exposure increases to 0.36 percentage points, and the estimated effect of winning increases to 0.54 percentage points. Although professional football is not particularly popular among Hispanics (Scarborough Research 2004), a similar pattern of results is obtained when we restrict the sample to the children of mothers who identified themselves as Hispanic: Super Bowl exposure is associated with a 0.34 percentage-point increase in the probability of low birth weight, and exposure to a Super Bowl win is associated with a 0.45 percentage-point increase in this probability.

Finally, the sample is divided based on the mother's marital status in Panel C of Table 5. We find that Super Bowl exposure is associated with an increased probability of having a low birth weight child for both married and single mothers. However, this increase is almost 5 times larger when the sample is restricted to children whose mothers were single. Likewise, exposure to a Super Bowl win is associated with an increased probability of low birth weight among both married and single women, but this increase is almost 5 times larger when the sample is restricted to the children of single women.

\subsection{Unexpected vs. expected Super Bowl outcomes}

One of the advantages to using the Super Bowl as a natural experiment is that we know the pre-game Las Vegas point spread. With this information, we can identify upset (i.e., unexpected) wins and losses. There is evidence that upsets generate particularly strong emotional responses (Rees and Schnepel 2009; Card and Dahl 2011); Card and Dahl (2011) argued that an upset loss can be thought of an exogenous, negative "emotional cue," sparking intimate partner violence at home. 
In this section, we extend our analysis by replacing SuperBowlat in equation (3) with 6 mutually exclusive variables based on the Las Vegas point spread and the work of Card and Dahl (2011):

1. Upset Win is equal to 1 if the NFL team located in area $a$ won the Super Bowl in year $t$ but was predicted to lose by 4 or more points (and is equal to 0 otherwise).

2. Unpredictable Win is equal to 1 if the NFL team located in area $a$ won the Super Bowl in year $t$ and the point spread was less than 4 (and is equal to 0 otherwise).

3. Predictable Win is equal to 1 if the NFL team located in area $a$ won the Super Bowl in year $t$ and was predicted to win by 4 or more points (and is equal to 0 otherwise).

4. Upset Loss is equal to 1 if the NFL team located in area $a$ lost the Super Bowl in year $t$ but was predicted to win by 4 or more points (and is equal to 0 otherwise).

5. Unpredictable Loss is equal to 1 if the NFL team located in area $a$ lost the Super Bowl in year $t$ and the point spread was less 4 (and is equal to 0 otherwise).

6. Predictable Loss is equal to 1 if the NFL team located in area $a$ lost the Super Bowl in year $t$ and was predicted to lose by 4 or more points (and is equal to 0 otherwise).

Thirty-six Super Bowls were played during the period under study. Nineteen of these Super Bowls produced an expected outcome (in other words, the closing Las Vegas point spread was greater than or equal to four and the favored team won). Six of these Super Bowls produced an upset (in other words, the closing Las Vegas point spread was greater than or equal to four and the underdog team won). The outcome of the remaining games was unpredictable.

Appendix Table 1 presents the Las Vegas point spreads and the outcomes of the 36 Super Bowls played over the period 1969-2004.

The results of this exercise are reported in column (3) of Table 6; to facilitate comparison, columns (1) and (2) of Table 6 reproduce estimates originally reported in Table 4. Among children who were likely conceived 1-4 months before the Super Bowl, loses (whether predicted or not) are essentially unrelated to low birth weight, whereas exposure to an upset win 
seems to sharply increase the risk of low birth weight. Specifically, exposure to an upset win is associated with a 0.47 percentage-point increase in the probability of having a child who weighed less than the 2,500 gram cutoff, which corresponds to a 6.4 percent increase in the incidence of low birth weight. Although the estimated coefficient of Unpredictable Win is small and statistically insignificant, exposure to a predicted win is associated with a 0.23 percentagepoint increase in the probability of low birth weight. ${ }^{27}$

\subsection{Gestation duration and month of conception}

Prenatal stress can affect birth weight through either intrauterine growth or gestation duration. In Table 7, we explore what happens to our estimates when gestation duration (in weeks) is used as a control. Interestingly, neither Super Bowl exposure, nor exposure to a Super Bowl win, is associated with low birth weight controlling for gestation duration. These results are consistent with those of Torche (2011), who found that weeks of gestation explained the relationship between earthquake exposure and birth weight. ${ }^{28}$

Next, we expand our sample to include children who were conceived 5-7 months before the Super Bowl and allow the impact of exposure to vary by month of conception. ${ }^{29}$ The results are reported in Table 8. Consistent with evidence from previous studies based on natural disasters or unexpected acts of violence, the results in Table 8 suggest that the effect of Super

\footnotetext{
${ }^{27}$ The estimated coefficients of predicted win, unpredictable win, and upset win are significantly different from each other at the 0.05 level.

${ }^{28}$ Although not reported in Table 7, we find that controlling for gestation duration reduces the estimated coefficient of Upset Win from 0.0047 to 0.0034 , while the estimated coefficient of Predicted Win becomes small and statistically insignificant. Upset losses are associated with a 0.39 percentage-point increase in the probability of low birth weight when gestation duration is included in the regression.

${ }^{29} \mathrm{We}$ do not estimate the effects of exposure among children conceived 8 or more months before the Super Bowl because most previous studies have found that psychological stress experienced after the first trimester is unrelated to birth outcomes (Paarlberg et al. 1999; Schneider et al. 1999; Glyn et al. 2001; Eskenazi et al. 2007; Camacho 2008; Torche 2011; Rees and Mansour 2012; Brown 2015). Moreover, a non-trivial proportion of children conceived 8 or more months before the Super Bowl were born before exposure could have taken place.
} 
Bowl exposure is strongest in the early stages of pregnancy. ${ }^{30}$ For instance, estimates of the effect of exposure to the Super Bowl are small and statistically insignificant for children conceived in July through October; among children conceived in November, Super Bowl exposure is associated with a 0.13 percentage-point increase in the probability of low birth weight; among children conceived in December, Super Bowl exposure is associated with a 0.23 percentage-point increase in this probability. Although exposure to a Super Bowl loss is associated with a 0.22 percentage-point increase in the probability of low birth weight among children conceived in December, this estimate is not significant at the .05 level.

\subsection{Behavioral Responses}

Could smoking mediate the relationship between Super Bowl exposure and low birth weight documented in Tables 3-8? There is little evidence that smoking during early pregnancy reduces birth weight (Bernstein et al. 2005; Jaddoe et al. 2008; Prabhu et al. 2010). ${ }^{31}$ Super Bowl exposure 1-4 months after conception could, however, cause ex-smokers to relapse. Between 57 and 77 percent of women smokers in the Unites States fail to quit smoking when they become pregnant (Schneider et al. 2010, p. 83), and failure to quit during pregnancy is positively related to self-reported stress (Grangé et al. 2006). ${ }^{32}$

In Table 9, we present estimates of the relationship between Super Bowl exposure and Tobacco Use (equal to 1 if the mother of child $i$ reported smoking while pregnant, and equal to 0

\footnotetext{
${ }^{30}$ Only one previous study based on a natural disaster or an unexpected act of violence has concluded that psychological stress experienced in the later stages of pregnancy can lead to low birth weight (Smits et al. 2006).

31 There is strong evidence that smoking in the second and third trimesters substantially increases the risk of having a low birth weight child (Bernstein et al. 2005; Jaddoe et al. 2008).

${ }^{32}$ It is also possible that pregnant women whose team advances to the Super Bowl are exposed to more second-hand smoke at Super Bowl parties than their counterparts whose team did not make it to the divisional playoff.
} 
otherwise). ${ }^{33}$ Because the NVSS did not include information on tobacco use prior to the 1989 revision of the Standard Certificate of Birth (Friedman 2007), these estimates are based on NVSS data for the period 1989-2004. The estimated relationship between Super Bowl exposure and tobacco use is positive and statistically significant at the .10 level. When SuperBowl is replaced with WonSuperBowl and LostSuperBowl in column (2), we find that winning the Super Bowl is associated with a 5 percent increase in the probability that child $i$ 's mother smoked during pregnancy $(0.55 / 10.86=0.051)$; losing the Super Bowl is associated with a small, statistically insignificant, reduction in this probability.

In column (3) of Table 9, SuperBowl is replaced by the 6 outcome variables based on the Las Vegas point spread. The results reported in column (3) of Table 9 are difficult to reconcile with the hypothesis that smoking mediates the relationship between Super Bowl exposure and low birth weight. Specifically, we find that predicted wins are associated with larger increases in tobacco use than either upset or unpredictable wins. ${ }^{34}$ In contrast, upset wins were associated with the largest increase in the probability of having a low birth weight child (Table 6). Likewise, the relationship between tobacco use and winning the Super Bowl appears to be stronger when the sample is restricted to children born to mothers who completed at least 4 years of high school, while the estimated relationship between winning the Super Bowl and low birth weight was strongest among children whose mothers did not complete 4 years of high school (Table 5) ${ }^{35}$ Although we cannot rule out the possibility that smoking mediates the relationship

\footnotetext{
${ }^{33}$ Almost 11 percent of the births in our sample were to women who reported smoking while pregnant. However, it should be noted that researchers have, by examining medical records, found that tobacco use is under-reported on birth certificates (Reichman and Hade 2001).

${ }^{34}$ It should be noted, however, that we cannot formally reject the hypothesis that these three coefficients are equal.

${ }^{35}$ Estimates of the relationship between Super Bowl exposure and tobacco use by mother's education, race, ethnicity, and marital status are available from the authors upon request.
} 
between Super Bowl exposure and low birth weight, these results suggest that it is not the primary mechanism.

Alcohol consumption represents another potential behavioral response to Super Bowl exposure. ${ }^{36}$ We report estimates of the relationship between Super Bowl exposure and alcohol consumption in Appendix Table 3. Exposure to a Super Bowl win is associated with a 31 percent increase in the incidence of alcohol use $(0.53 / 1.6=0.313) .{ }^{37}$ This estimate, however, should be interpreted with caution. According to the Centers for Disease Control (2009), approximately 12 percent of pregnant women drink, while only two percent of children in our sample were born to mothers who reported consuming alcohol. ${ }^{38}$

\section{CONCLUSION}

Medical studies have documented a positive association between psychological stress experienced during pregnancy and low birth weight (Beydoun and Saftlas 2008). Studies that exploit earthquakes (Glyn et al. 2001; Torche 2011), terrorist attacks (Eskenazi et al. 2007) or the loss of a close relative (Black et al. 2014; Persson and Rossin-Slater 2014) provide evidence that this association may be causal, but natural disasters and unexpected acts of extreme violence

\footnotetext{
${ }^{36}$ Moderate drinking, typically defined as a maximum of one drink per day, is only weakly related to birth weight, but there is evidence that heavy drinking leads to an increased risk of having a low birth weight child (Patra et al. 2011).

${ }^{37}$ Stoecker et al. (forthcoming) found that advancing to the Super Bowl was associated with more influenza deaths among the elderly, a result these authors attributed to increased "local socialization". However, there is no evidence of a relationship between first-trimester exposure to influenza and birth weight. In fact, Kelly (2011) found that second-trimester exposure to influenza reduced birth weight, whereas Currie and Schwandtz (2013) and Schwandt (2014) found that third-trimester exposure to influenza was associated with low birth weight.

${ }^{38}$ When the sample is restricted to these years, the estimated relationship between Super Bowl exposure and low birth weight, although positive, is not statistically significant at conventional levels. Specifically, Super Bowl exposure is associated with a (statistically insignificant) 0.07 percentage-point increase in the probability of low birth weight; exposure to a Super Bowl loss is associated with a (statistically insignificant) 0.04 percentage-point increase in this probability; and exposure to a Super Bowl win is associated with a (statistically insignificant) 0.09 percentage-point increase in this probability.
} 
could potentially limit access to prenatal care or reduce the availability of nutrient-rich food, while the death of a parent or sibling could affect the financial resources available to a family.

Drawing on publicly available data from the National Vital Statistics System (NVSS) for the period 1969-2004, this study estimates the effect of Super Bowl exposure on low birth weight. We find that winning the Super Bowl is associated with a 5.1 percent increase in the incidence of low birth weight (defined as weighing less than 2,500 grams at birth). Upset wins, which can be thought of as exogenously generated positive emotional cues (Card and Dahl 2011), lead to larger increases in the incidence of low birth weight than predicted wins. When we control for gestation length, the estimated relationship between wins and low birth weight is eliminated, suggesting that positive emotional cues do not influence birth weight through intrauterine growth.

While exposure to the Super Bowl elicits strong emotions, the event itself does not have other, potentially confounding, effects such as reducing access to prenatal care or nutrient-rich food. Nevertheless, exposure to the Super Bowl could affect the behavior of pregnant women as well as the behavior of their partners and friends. In fact, we find that winning the Super Bowl is associated with increased tobacco and alcohol use during pregnancy, but, because of data limitations, we cannot explore the effect of Super Bowl exposure on intimate-partner violence or the use of illegal substances such as marijuana. At a minimum, our results suggest that psychological stress is the first step along the causal pathway.

Recent studies have found that negative emotional cues resulting from, for instance, the loss of a parent can affect fetal health (Black et al. 2014; Persson and Rossin-Slater 2014). To our knowledge, ours is the first study to examine the relationship between a positive emotional 
cue and birth outcomes. The results suggest that future research on this topic might profitably explore a broader set of circumstances and events. 


\section{REFERENCES}

Aizer, Anna Laura Stroud, Stephen Buka. 2012. "Maternal Stress and Child Outcomes: Evidence from Siblings." NBER Working Paper No. 18422

Almond, Douglas and Janet Currie. 2011. "Killing Me Softly: The Fetal Origins Hypothesis." Journal of Economic Perspectives, Vol. 25, No. 3, pp. 153-172.

Almond, Douglas and Bhashkar Mazumder. 2011. "Health Capital and the Prenatal Environment: The Effect of Ramadan Observance during Pregnancy." American Economic Journal: Applied Economics, Vol. 3, No., 4, pp. 56-85.

Bernstein, Ira M., Joan A. Mongeon, Gary J. Badger, Laura Solomon, Sarah H. Heil, and Stephen T. Higgins, 2005. "Maternal Smoking and its Association with Birth Weight." Obstetrics and Gynecology, Vol. 106, No. 5, pp. 986-991.

Bertrand, Marianne, Esther Duflo, and Sendhil Mullainathan. 2004. "How Much Should We Trust Differences-in-Differences Estimates? Quarterly Journal of Economics, Vol. 119, No. 1, pp. 249-276.

Beydoun, Hind, and Audrey F. Saftlas. 2008. "Physical and Mental Health Outcomes of Prenatal Maternal Stress in Human and Animal Studies: A Review of Recent Evidence." Paediatric and Perinatal Epidemiology, Vol. 22, No. 5, pp. 438-466.

Bien, Louis. 2015. “The 2015 Salary Cap Explained.” SB Nation. http://www.sbnation.com/nfl/2015/3/2/8134891/nfl-salary-cap-2015-franchise-tag-explained

Black, Sandra, Paul Devereux, and Kjell Salvanes. 2007. "From the Cradle to the Labour Market? The Effect of Birth Weight on Adult Outcomes." Quarterly Journal of Economics, Vol. 122, No. 1, pp. 409-439.

Black, Sandra, Paul Devereux, and Kjell Salvanes. 2014. "Does Grief Transfer Across Generations? In-Utero Deaths and Child Outcomes.” NBER Working Paper No. 19979.

Block, Melissa. 2015. "NBC Courts Women In Hopes Of Record Super Bowl Broadcast." National Public Radio, January 30. Available at: http://www.npr.org/2015/01/30/382717161/nbc-courts-women-in-hopes-of-record-super-bowlbroadcast

Brown, Walter A., Alan D. Sirota, Raymond Niaura, and Tilmer O. Engebretson. 1993. "Endocrine Correlates of Sadness and Elation." Psychosomatic Medicine, Vol. 55, No. 5, pp. 458-467. 
Brown, Ryan. 2015. "The Mexican Drug war and Early-Life Health: The Impact of Violent Crime on Birth Outcomes." Working paper, University of Colorado Denver. Available at: http://sites.duke.edu/ryanbrown/research/

Camacho, Adriana. 2008. "Stress and Birth Weight: Evidence from Terrorist Attacks." The American Economic Review, Vol. 98, No. 2, pp. 511-515.

Card, David and Gordon B. Dahl. 2011. "Family Violence and Football: The Effect of Unexpected Emotional Cues on Violent Behavior" Quarterly Journal of Economics, Vol. 126, No. 1, pp. 103-143.

Centers for Disease Control and Prevention. 2008. "QuickStats: Mean Gestational Age, by Plurality--United States, 2005.” MMWR, Vol. 57, No. 9, p. 238.

Centers for Disease Control and Prevention. 2009. "Alcohol Use among Pregnant and Nonpregnant Women of Childbearing Age - United States, 1991-2005." MMWR, Vol. 58, No. 19, pp. 529-32.

Cunningham, Todd. 2012 "Super Bowl: Viewer Gender Gap Is Narrowing." The Wrap, February 01. Available at: http://www.thewrap.com/tv/article/super-bowl-viewer-gender-gapnarrowing-35005

Currie, Janet, Michael Greenstone, and Enrico Moretti. 2011. "Superfund Cleanups and Infant Health.” American Economic Review, Vol. 101, No. 3, pp. 435-441.

Currie, Janet and Reed W. Walker. 2011. "Traffic Congestion and Infant Health: Evidence from E-ZPass.” American Economic Journal: Applied Economics, Vol. 3, No. 1, pp. 65-90.

Currie, Janet and Maya Rossin-Slater. 2013. "Weathering the Storm: Hurricanes and Birth Outcomes.” Journal of Health Economics, Vol. 32, No. 3, pp. 487-503.

Currie, Janet, and Hannes Schwandt. 2013. "Within-Mother Analysis of Seasonal Patterns in Health at Birth." Proceedings of the National Academy of Sciences of the United States of America, Vol, 110, No. 30, pp. 12265-12270.

Dejohn, Irving. 2014. "Sleepless in Seattle: Seahawks Fans Celebrate Super Bowl XLVIII Victory with all Night Party and Riots." The Daily News, February 3. Available at: http://www.nydailynews.com/news/national/seattle-residents-celebrate-seahawks-super-bowlwin-article-1.1600079

de Weerth, Carolina, and Jan K. Buitelaar. 2005. "Physiological Stress Reactivity in Human Pregnancy. A Review." Neuroscience and Biobehavioral Reviews, Vol. 29, No. 2, pp. 295-312. Donahue, Sara M. A., Ken P. Kleinman, Matthew W. Gillman, and Emily Oken. 2010. "Trends in Birth Weight and Gestational Length among Singleton Term Births in the United States: 19902005." Obstetrics and Gynecology, Vol. 115, No 2 (Part 1), pp. 357-364. 
Erb, Kelly Phillips. 2015. "Salaries, Ads \& Security: What's The Real Cost Of Super Bowl XLIX?" Forbes, February 1. Available at:

http://www.forbes.com/sites/kellyphillipserb/2015/02/01/salaries-ads-security-whats-the-realcost-of-super-bowl-xlix/

Eskenazi, Brenda, Amy R. Marks, Ralph Catalano, Tim Bruckner, and Paolo G. Toniolo. 2007. "Low Birthweight in New York City and Upstate New York Following the Events of September 11th." Human Reproduction, Vol. 22, No.11, pp. 3013-3020.

Farmer, Amy and Jill Tiefenthaler. 2003. "Explaining the Recent Decline in Domestic Violence.” Contemporary Economic Policy, Vol. 21, No. 2, pp. 158-172.

Friedman, Daniel J. 2007. "Assessing Changes in the Vital Statistics Records and Statistics Infrastructure.” Final Report, Population and Public Health Information Service.

Gandar, John, Richard Zuber, Thomas O’Brien, and Ben Russo. 1988. "Testing Rationality in the Point Spread Betting Market,” Journal of Finance, Vol. 43, No. 4, pp. 995-1008.

Gerra, G., A. Zaimovic, D. Franchini, M. Palladino, G. Giucastro, N. Reali, D. Maestric, R. Caccavaria, R. Delsignored, and F. Brambillae 1998. "Neuroendocrine Responses of Healthy Volunteers to 'Techno-Music': Relationships with Personality Traits and Emotional State." International Journal of Psychophysiology, Vol. 28, No. 1, pp. 99-111.

Glyn, Laura M., Pathik D. Wadha, Christine Dunkel-Schetter, Aleksandra Chicz-Demet, and Curt A. Sandman. 2001. "When Stress Happens Matters: Effects of Earthquake Timing on Stress Responsivity in Pregnancy." American Journal of Obstetrics and Gynecology, Vol. 184, No. 4, pp. 637-642.

Gorman, Bill. 2009. "Super bowl TV Ratings." TV by the Numbers, January 18. Available at: http://tvbythenumbers.zap2it.com/2009/01/18/historical-super-bowl-tv-ratings/11044

Grange', Gilles, Christophe Vayssiere, Anne Borgne, Albert Ouazana, Jean-Pierre L'Huillier, Paul Valensi, Gerard Peiffer, Henri-Jean Aubin, Dominique Renon, Daniel Thomas, and Francois Lebargy. 2006. "Characteristics of Tobacco Withdrawal in Pregnant Women." European Journal of Obstetrics and Gynecology and Reproductive Biology Vol. 125, No. 1, pp. 38-43.

Heffner, Kathi L., Janice K. Kiecolt-Glaser, Timothy J. Loving, Ronald Glaser, and William B. Malarkey. 2004. "Spousal Support Satisfaction as a Modifier of Physiological Responses to Marital Conflict in Younger and Older Couples." Journal of Behavioral Medicine, Vol. 27, No. 3, pp. 233-254.

Hirschhorn, Jason. 2015. "City of Seattle Plans Post-Super Bowl Celebration.” February 2, SB Nation, Available at: http://www.sbnation.com/nfl/2015/2/2/7964719/city-seattle-seahawksplans-post-super-bowl-2015-celebration 
Hinckley, David. 2014. "Oscars 2014: Academy Awards Telecast Big Winner, Notching Highest Ratings in 10 Years." New York Daily News, March 3. Available at:

http://www.nydailynews.com/entertainment/oscars/oscar-telecast-draws-highest-ratings-tenyears-article-1.1709319

Hubert, Walter. Mathilde Moller, and Renate de Jong-Meyer. 1993. "Film-Induced Amusement Changes in Saliva Cortisol Levels." Psychoneuroendocrinology, Vol. 18, No. 4, pp. 265-272.

Jaddoe, Vincent W., Ernst-Jan W. M. Troe, Albert Hofman' Johan P. Mackenbach, Henriette A. Moll, Eric A. P. Steegers, and Jacqueline C. M. Witteman 2008. "Active and Passive Maternal Smoking during Pregnancy and the Risks of Low Birthweight and Preterm Birth: The Generation R Study." Paediatric and Perinatal Epidemiology, Vol. 22, No. 2, pp.162-171.

Jones, Jeffrey M. 2001. "More Americans are Fans of Pro Football than Any Other Sport." Gallup News Service, April 20. Available at: http://www.gallup.com/poll/1786/more-americansfans-pro-football-than-any-other-sport.aspx

Jones, Jeffrey M. 2005. "Six in 10 Americans Are Pro Football Fans." Gallup News Service, February 4. Available at: http://www.gallup.com/poll/14812/six-americans-pro-footballfans.aspx

Kaempf, Joseph W., Mark Tomlinson, Cindy Arduza, Shelly Anderson, Betty Campbell, Linda A. Ferguson, Mara Zabari, Valerie T. Stewart. 2006. "Medical Staff Guidelines for Periviability Pregnancy Counseling and Medical Treatment of Extremely Premature Infants." Pediatrics, Vol. 117, No. 1, pp. 22-29.

Kelly, Elaine. 2011. "The Scourge of Asian Flu: In Utero Exposure to Pandemic Influenza and the Development of a Cohort of British Children." The Journal of Human Resources, Vol. 46, No. 4, pp. 669-694.

Kemmer, Friedrich W., Rolf Bisping, Hans J. Steingrüber, Helmut Baar, Frank Hardtmann, Reiner Schlaghecke, and Michael Berger. 1986. "Psychological Stress and Metabolic Control in Patients with Type I Diabetes Mellitus." New England Journal of Medicine, Vol. 314, No. 17, pp. 1078-1084.

Kiecolt-Glaser, Janice K., Tamara Newton, John T. Cacioppo, Robert C. MacCallum, Ronald Glaser, and Willima B. Malarkey. 1996. "Marital Conflict and Endocrine Function: Are Men Really More Physiologically Affected than Women?" Journal of Consulting and Clinical Psychology, Vol. 64, No. 2, pp. 324-332.

Kloner, Robert A., Scott A. McDonald, Justin Leekaa, and W. Kenneth Poole. 2009. "Comparison of Total and Cardiovascular Death Rates in the Same City during a Losing versus Winning Super Bowl Championship." American Journal of Cardiology, Vol. 103, No. 12, pp. 1647-1650. 
Khashan, Ali S., Roseanne McNamee, Kathryn M. Abel, Marianne G. Pedersen, Roger T. Webb, Louise C. Kenny, Preben Bo Mortensen, and Philip N. Baker. 2008. "Reduced Infant Birthweight Consequent Upon Maternal Exposure to Severe Life Events." Psychosomatic Medicine, Vol. 70, No., 6, pp. 688-694.

Kirschbaum, Clemens, Jens C. Prussner, Arthur A. Stone, Ilona Federenko, Jens Gaab, Doris Lintz, Nicole Schommer and Dirk H. Hellhammer 1995. "Persistent High Cortisol Responses to Repeated Psychological Stress in a Subpopulation of Healthy Men." Psychosomatic Medicine, Vol. 57, No. 5, pp. 468-474.

Lacitis, Erik. 2014. “700,000 at Seahawks Parade? Doesn't Add Up, Experts Say.” The Seattle Times, February 8. Available at: http://www.seattletimes.com/seattle-news/700000-at-seahawksparade-doesnrsquot-add-up-experts-say

López, Hassan H., Aleena C. Hay, and Phoebe H. Conklin. 2009. “Attractive Men induce Testosterone and Cortisol Release in Women." Hormones and Behavior, Vol. 56, No. 1, pp. 8492.

Lumey, L. H., and Aryeh D. Stein. 1997. "Offspring Birth Weights after Maternal Intrauterine Undernutrition: A Comparison within Sibships." American Journal of Epidemiology, Vol. 146, No. 10, pp. 810-819

Mansour, Hani and Daniel I. Rees. 2012. "Armed Conflict and Birth Weight: Evidence from the al-Aqsa Intifada.” Journal of Development Economics, Vol. 99, No. 1, pp. 190-199.

Martin, Joyce A., Hsiang-Ching Kung, T.J. Mathews, Donna L. Hoyert, Donna M. Strobino, Bernard Guyer, and Shae R. Sutton. 2008. "Annual Summary of Vital Statistics: 2006." Pediatrics, Vol. 121, No. 4, pp. 788-801.

Morgan, Maria A., Robert L. Goldenberg, and_Jay Schulkin· 2008. “Obstetrician-Gynecologists' Practices Regarding Preterm Birth at the Limit of Viability." Journal of Maternal-Fetal and Neonatal Medicine, Vol. 21, No. 2, pp. 115-121.

Mulder, E.J.H., P.G. Robles de Medina, A.C. Huizink, B.R.H. Van den Bergh, J.K. Buitelaar, G.H.A. Visser. 2002. "Prenatal Maternal Stress: Effects on Pregnancy and the (Unborn) Child." Early Human Development, Vol. 70, No. 1-2. pp. 3-14.

Muret, Don. 2014. "Merchandise Record in NFL's Sights.” Sports Business Journal, January 20. Available at: http://www.sportsbusinessdaily.com/Journal/Issues/2014/01/20/Super-Bowl/SBmerchandise.aspx

Nielsen Media and Entertainment, 2015. "NFL Fans Make Every Game a Super Bowl," Nielsen Newswire, Available at: www.nielsen.com/us/en/insights/news/2015/nfl-fans-make-every-gamea-super-bowl.html 
Paarlberg, Marieke K., J. J. M. Vingerhoets, Jan Passchier, Gustaaf A. Dekker, Antonius G. J. J. Heinen, and Herman P. van Geijn. 1999. "Psychosocial Predictors of Low Birthweight: A Prospective Study." British Journal of Obstetrics and Gynaecology, Vol. 106, No. 8, pp. 834-41.

Patra, J., R. Bakker, H. Irving, V. Jaddoe, S. Malini, and J. Rehm. 2011. "Dose-Response Relationship between Alcohol Consumption before and during Pregnancy and the Risks of Low Birthweight, Preterm Birth and Small for Gestational Age (SGA) - A Systematic Review and Meta-Analyses." BJOG, Vol. 118, No. 12, pp. 1411-1421.

Peeters, Frenk, Nancy A. Nicholson, and Johannes Berkhof. 2003. "Cortisol Responses to Daily Events in Major Depressive Disorder.” Psychosomatic Medicine, Vol. 65, No. 5, pp. 836-841.

Persson, Petra and Maya Rossin-Slater. 2014. "Family Ruptures and Intergenerational Transmission of Stress.” EconPapers, No. 1022. Available at: http://econpapers.repec.org/paper/hhsiuiwop/1022.htm

Prabhu, Nanda, Norman Smith, Doris Campbell, Leone C Craig, Anthony Seaton, Peter J. Helms, Graham Devereux, and Stephen W Turner. 2010. "First Trimester Maternal Tobacco Smoking Habits and Fetal Growth.” Thorax, Vol. 65, No. 3, pp. 235-240.

Rees, I. Daniel and Kevin T. Schnepel. 2009. "College Football Games and Crime." Journal of Sports Economics, Vol. 10, No. 1, pp. 168-187.

Reichman, Nancy E., and Erinn M. Hade. 2001. "Validation of Birth Certificate Data: A Study of Women in New Jersey's Health Start Program.” Annals of Epidemiology, Vol. 11, No. 3, pp. 186-93.

Royer, Heather. N. 2009. "Separated at Girth: US Twin Estimates of the Long-Run and Intergenerational Effects of Fetal Nutrients." American Economic Journal: Applied Economics, Vol. 1, No. 1, pp. 49-85.

Scarborough Research. 2004. "Get to Know the NFL Fan.” Street \& Smith Sports Business Daily, September 6. Available at: http://www.sportsbusinessdaily.com/article/106148

Schneider Mary L., Elizabeth C. Roughton, Alyssa J. Koehler, and Gabriele R. Lubach. 1999. "Growth and Development Following Prenatal Stress Exposure in Primates: An Examination of Ontogenetic Vulnerability.” Child Development, Vol. 70, No. 2, pp. 263- 274.

Schneider, Sven, Christina Huy, Jessica Schutz, and Katharina Diehl. 2010. "Smoking Cessation during Pregnancy: A Systematic Literature Review." Drug and Alcohol Review, Vo. 29, No. 1, pp. 81-90.

Schwandt, Hannes. 2014. "The Lasting Legacy of Seasonal Influenza: In-Utero Exposure and Human Capital Development." Working paper, Princeton University, Center for Health and Wellbeing. Available at: http://scholar.princeton.edu/schwandt/job-market-paper 
Smits, Luc, Lydia Krabbendam, Rob de Bie, Gerard Essed, and Jim van Os. 2006. "Lower Birth Weight of Dutch Neonates who were in Utero at the Time of the 9/11 Attacks." Journal of Psychosomatic Research, Vol. 61, No. 5, pp. 715-717.

Stoecker, Charles, Nicholas J. Sanders, and Alan Barreca. Forthcoming. "Success is Something to Sneeze at: Influenza Mortality in Regions that Send Teams to the Super Bowl." American Journal of Health Economics.

Testa, R., A. Basso, L. Piantanelli, G. Coppa, A. Recchioni, G. De Sio, I. Testa, A.R. Bonfigli, and P. Dipaola. 1994. "Blood Catecholamine Levels and Lymphocyte Betaadrenoceptors Following Acute Noise Stress." Bollettino della Societa Italiana di Biologia Sperimentale, Vol. 70, No. 8-9, pp. 193-198.

Torche, Florencia. 2011. "The Effect of Maternal Stress on Birth Outcomes: Exploiting a Natural Experiment.” Demography, Vol. 48, No. 4, pp. 1473-1491.

van der Meij, Leander, Abraham P. Buunk, and Alicia Salvador. 2010. "Contact with Attractive Women affects the Release of Cortisol in Men." Hormones and Behavior, Vol. 58, No. 3, pp. $501-505$.

van der Meij, Leander, Mercedes Almela, Vanesa Hidalgo, Carolina Villada, Hans IJzerman, Paul A. M. van Lange, Alicia Salvador. 2012. "Testosterone and Cortisol Release among Spanish Soccer Fans Watching the 2010 World Cup Final.” PLoS ONE, Vol. 7, No. 4, p. e34814.

Wadhwa, Pathik D., Thomas J. Garite, Manuel Porto, Laura Glynn, Aleksandra Chicz-DeMet, Christine Dunkel-Schetter, and Curt A. Sandman. 2004. "Placental Corticotropin-Releasing Hormone (CRH), Spontaneous Preterm Birth, and Fetal Growth Restriction: A Prospective Investigation." American Journal of Obstetrics and Gynecology, Vol. 191, No. 4, pp. 1063-1069.

Wilbert-Lampen, Ute, David Leistner, Sonja Greven, Tilman Pohl, Sebastian Sper, Christoph Völker, Denise Güthlin. Andrea Plasse, Andreas Knez, Helmut Küchenhoff, and Gerhard Steinbeck. 2008. "Cardiovascular Events during World Cup Soccer." The New England Journal of Medicine, Vol. 358, No. 5, pp. 475-483.

White, F. Garland, Janet Katz, and Kathryn E. Scarborough. 1992. "The Impact of Football Games Upon Violent Assualts on Women.” Violence and Victims, Vol. 7, pp. 157-171.

Young, David. 2014. “Congrats, NFL, You Own Parity.” Sports Grid. Available at: http://www.sportsgrid.com/nfl/congrats-nfl-you-own-parity/ 


\section{Figure 1: Percent low birth weight $(<2,500 g)$ babies in the years in and surrounding Super}

Bowl runs

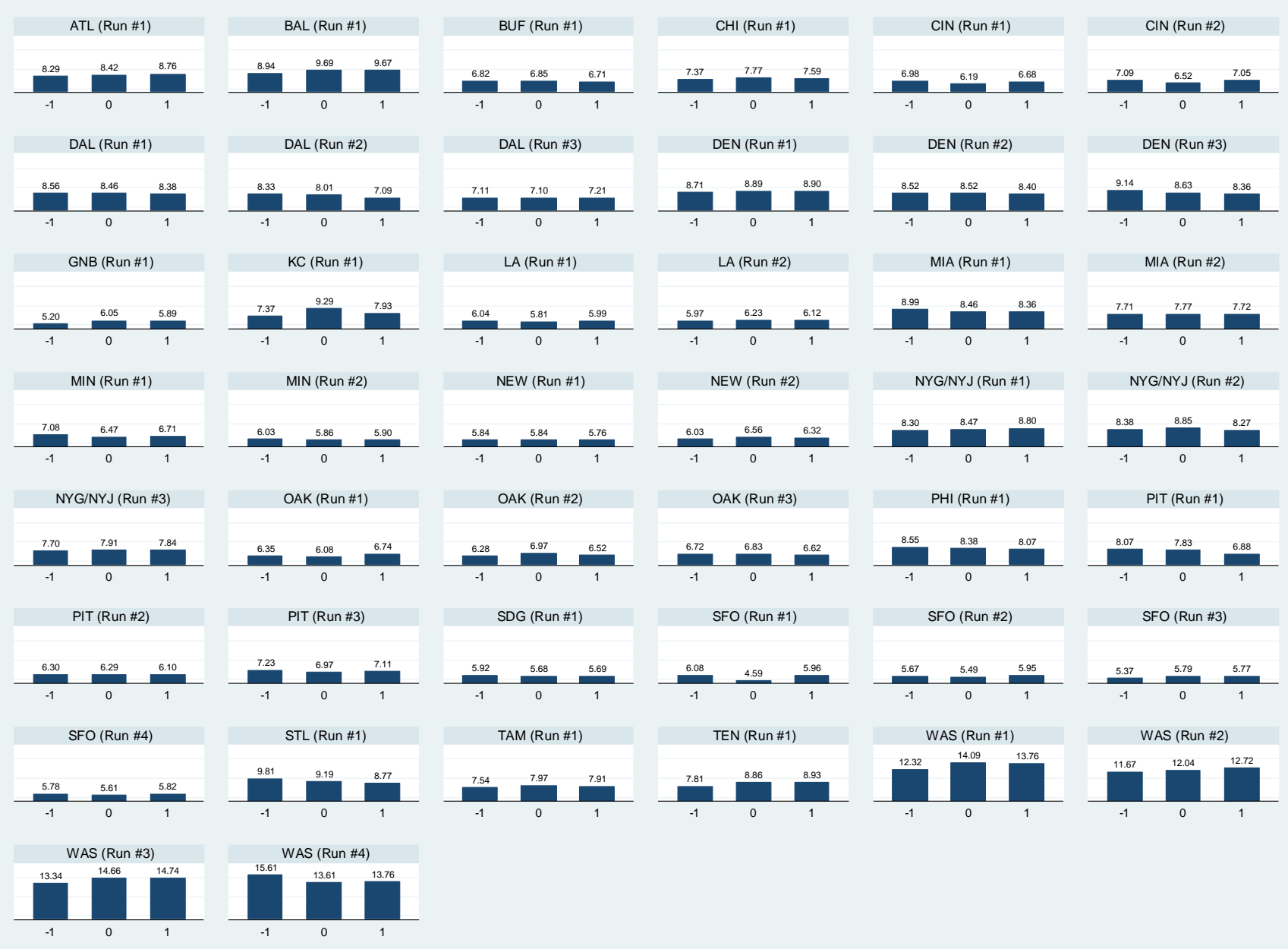

Source: National Center for Health Statistics, Vital Statistics Data, 1969-2004.

Notes: The sample includes children who were conceived by mothers living in an NFL fan base area in October, November, or December. A super bowl year (year zero) is all of the years the NFL team played in the super bowl during a super bowl run. If a team played in two super bowls with a one year gap in between, then the gap year is excluded from the sample. Year "-1" is the year before a super bowl appearance, or the year before the first in a series of back-to-back super bowl appearances with no more than a one year gap. Year "1" is the year after a super bowl appearance, or the year after the last in a series of back-to-back super bowl appearances with no more than a one year gap. 


\section{Figure 2: Average birth weight in grams and percent low birth weight $(<2,500 g)$ babies in the years in and surrounding super bowl runs}

A. Low birth weight $(<2,500 \mathrm{~g})$

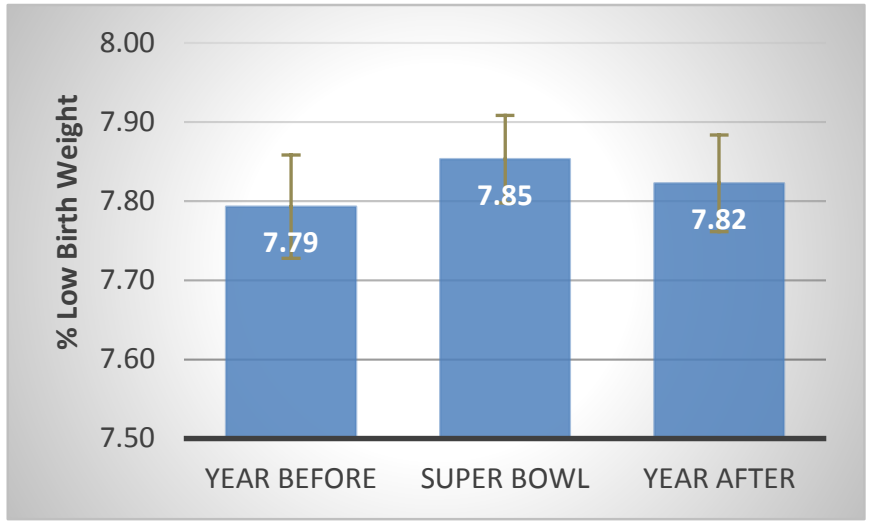

C. Birth weight in grams

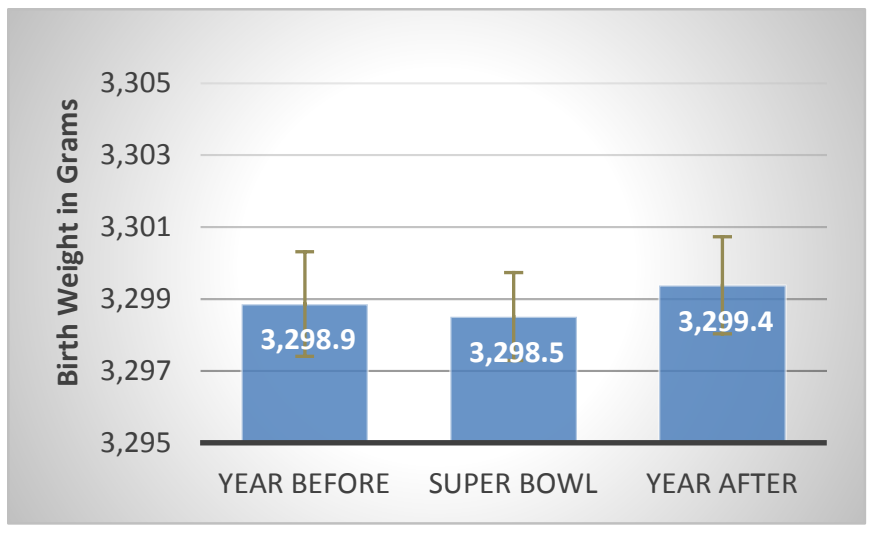

B. Low birth weight $(<2,500 \mathrm{~g})$ residuals

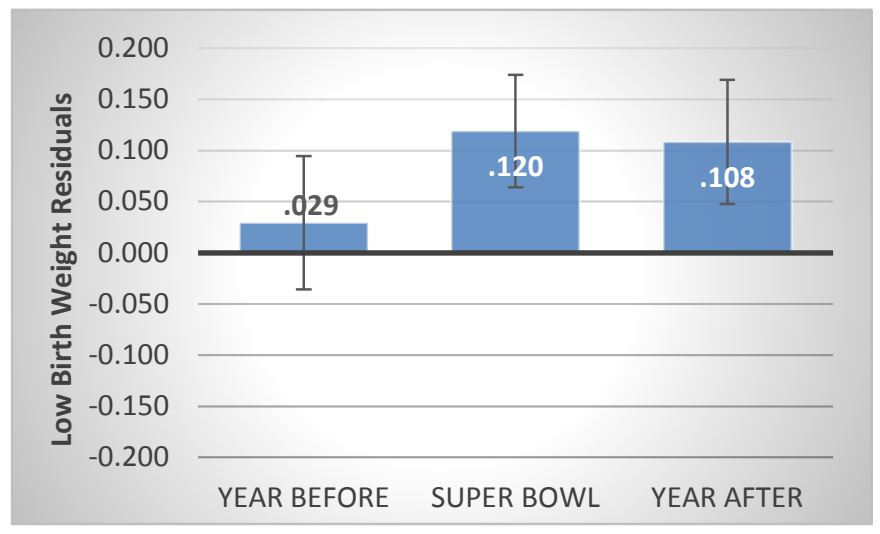

D. Birth weight in grams residuals

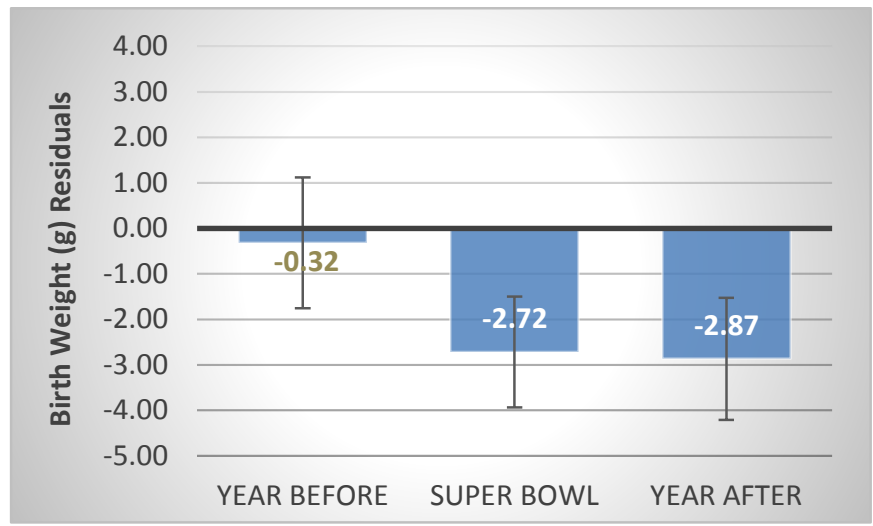

Source: National Center for Health Statistics, Vital Statistics Data, 1969-2004.

Notes: The sample includes children who were conceived by mothers living in an NFL fan base area in October, November, or December. Confidence intervals are at the ninety percent confidence level. The average residuals are calculated from regressions that includes area fixed effects, year fixed effects, and area-specific linear time trends. A super bowl year is the year the NFL team played in the super bowl or all years the NFL team played in the super bowl during a run of back-to-back super bowl appearances. If a team played in two super bowls with a one year gap in between, then the gap year is excluded from the sample and the super bowl run continues. Defined in this way, there are 44 super bowl runs during the sample period. Year before is the year before a super bowl run. Year after is the year after a super bowl run. The averages displayed give equal weight to each of the 44 super bowl runs. Averages that give equal weight to each birth produce a similar pattern. 
Table 1. Descriptive statistics

\begin{tabular}{|c|c|}
\hline Birth outcomes & Full Sample \\
\hline Birth weight (in grams) & $\begin{array}{c}3,314.2 \\
(.2)\end{array}$ \\
\hline Low birth weight $(<2,500 \mathrm{~g})$ & .073 \\
\hline Gestation length (in weeks) & $\begin{array}{c}39.0 \\
(.001)\end{array}$ \\
\hline Preterm birth ( $<35$ weeks gestation $)$ & .097 \\
\hline Multiple birth & .024 \\
\hline Born in hospital & .987 \\
\hline Father indicated on birth certificate & .886 \\
\hline \multicolumn{2}{|l|}{ Mother's characteristics } \\
\hline Age & $\begin{array}{c}26.6 \\
(.002)\end{array}$ \\
\hline Married & .639 \\
\hline Unknown marital status & .088 \\
\hline First born child & .410 \\
\hline White & .752 \\
\hline Black & .196 \\
\hline Asian & .045 \\
\hline Other Race & .008 \\
\hline Hispanic & .194 \\
\hline Unknown Hispanic origin & .256 \\
\hline Less than four high school & .207 \\
\hline Four years of high school or some college & .455 \\
\hline Four or more years of college & .171 \\
\hline Education not reported & .166 \\
\hline Alcohol Use & .016 \\
\hline Drinks per week (among alcohol users) & $\begin{array}{c}2.9 \\
(.022)\end{array}$ \\
\hline Tobacco Use & .109 \\
\hline Tobacco use per day (among tobacco users) & $\begin{array}{l}11.7 \\
(.01)\end{array}$ \\
\hline Sample Size & $12,179,714$ \\
\hline
\end{tabular}

Source: National Center for Health Statistics, Vital Statistics Data, 1969-2004.

Notes: Standard errors for continuous variables are shown in parentheses. The sample includes children who were conceived by mothers living in an NFL fan base area in October, November, or December. Month of conception was assigned using gestation duration (in weeks) and month of birth. NFL fan base area was assigned using the mother's county of residence. If an NFL stadium was located in a county at any time during the period 1969 through 2004, then that county and its neighboring counties constitute an NFL fan base area. Hispanic origin questions first appear in the Vital Statistics Data in 1978; substance use questions first appear in in 1988. 
Table 2: The relationship between the Super Bowl and mother and birth characteristics.

\begin{tabular}{|c|c|c|c|}
\hline Mother's characteristics: & & Birth characteristics: & \\
\hline$\overline{\text { Black }}$ & $\begin{array}{l}.0014 \\
(.0011)\end{array}$ & Multiple birth & $\begin{array}{l}.0008 \\
(.0005)\end{array}$ \\
\hline Asian & $\begin{array}{l}.0020 \\
(.0017)\end{array}$ & First birth & $\begin{array}{c}.0001 \\
(.0004)\end{array}$ \\
\hline Other race & $\begin{array}{l}.0104 \\
(.0076)\end{array}$ & First birth not reported & $\begin{array}{l}.0039 \\
(.0157)\end{array}$ \\
\hline Hispanic & .0029 & Father indicated & $\begin{array}{l}.0025 \\
(.0030)\end{array}$ \\
\hline Hispanic origin not reported & $\begin{array}{c}(.0017) \\
.0014\end{array}$ & Female birth & $\begin{array}{l}-.0002 \\
(.0002)\end{array}$ \\
\hline & $(.0370)$ & Born in hospital & $\begin{array}{l}.0065 \\
(.0091)\end{array}$ \\
\hline Less than four years high school & $\begin{array}{l}-.0022 \\
(.0013)\end{array}$ & Hospital birth not reported & $\begin{array}{c}.0006 \\
(.0164)\end{array}$ \\
\hline Four or more years of college & $\begin{array}{l}.0018 \\
(.0011)\end{array}$ & Conceived in October & $\begin{array}{l}-.00015 \\
(.0002)\end{array}$ \\
\hline Education not reported & $\begin{array}{l}-.0288 \\
(.0347)\end{array}$ & Conceived in November & $\begin{array}{l}-.0001 \\
(.0002)\end{array}$ \\
\hline Age $14-16$ & $\begin{array}{l}.0016 \\
(.0010)\end{array}$ & Sample Size & $12,179,714$ \\
\hline Age $17-19$ & $\begin{array}{l}.0010 \\
(.0005)\end{array}$ & $\begin{array}{l}\text { F-stat for control variables } \\
\text { Partial } R^{2} \text { for control variables }\end{array}$ & $\begin{array}{l}14.32 \\
.0004\end{array}$ \\
\hline Age $20-24$ & $\begin{array}{l}.0005 \\
(.0003)\end{array}$ & & \\
\hline Age 30 - 34 & $\begin{array}{l}-.0001 \\
(.0005)\end{array}$ & & \\
\hline Age $35-39$ & $\begin{array}{l}.0012 \\
(.0006)\end{array}$ & & \\
\hline Age $40-44$ & $\begin{array}{l}.00114 \\
(.0008)\end{array}$ & & \\
\hline Age $45-50$ & $\begin{array}{l}-.00002 \\
(.0026)\end{array}$ & & \\
\hline Married & $\begin{array}{l}-.0013 \\
(.0016)\end{array}$ & & \\
\hline Marital status not reported & $\begin{array}{l}-.0388 \\
(.0556)\end{array}$ & & \\
\hline
\end{tabular}

${ }^{*}$ Statistically significant at $10 \%$ level; ${ }^{* *}$ at $5 \%$ level; ${ }^{* * *}$ at $1 \%$ level.

Notes: Standard errors clustered at the NFL fan base level are shown in parentheses. The reported regression is a single linear probability model with making it to the Super Bowl as the dependent variable. The regression includes year fixed effects, area fixed effects, and area-specific linear time trends. 
Table 3. The relationship between birth weight and Super Bowl exposure

\begin{tabular}{|c|c|c|c|c|c|c|}
\hline & \multicolumn{3}{|c|}{ Low Birth Weight $(<2,500 \mathrm{~g})$} & \multicolumn{3}{|c|}{ Birth Weight in Grams } \\
\hline & $(1)$ & $(2)$ & (3) & (4) & $(5)$ & $(6)$ \\
\hline Lost in Divisional Playoffs & $\begin{array}{l}-.0003 \\
(.0003)\end{array}$ & $\begin{array}{l}-.0002 \\
(.0003)\end{array}$ & $\begin{array}{l}-.0001 \\
(.0002)\end{array}$ & $\begin{array}{c}.69 \\
(1.59)\end{array}$ & $\begin{array}{l}-.77 \\
(.76)\end{array}$ & $\begin{array}{l}-.63 \\
(.69)\end{array}$ \\
\hline Lost in Conference Playoffs & $\begin{array}{l}-.0009 \\
(.0009)\end{array}$ & $\begin{array}{l}-.0005 \\
(.0006)\end{array}$ & $\begin{array}{l}-.0007^{*} \\
(.0004)\end{array}$ & $\begin{array}{c}7.14^{*} \\
(4.03)\end{array}$ & $\begin{array}{c}1.84 \\
(1.43)\end{array}$ & $\begin{array}{l}2.49^{* *} \\
(1.17)\end{array}$ \\
\hline Played in Super Bowl & $\begin{array}{c}.0014^{*} \\
(.0008)\end{array}$ & $\begin{array}{c}.0012^{* *} \\
(.0005)\end{array}$ & $\begin{array}{l}.0013^{* * * *} \\
(.0004)\end{array}$ & $\begin{array}{l}-1.95 \\
(3.40)\end{array}$ & $\begin{array}{l}-3.12^{* *} \\
(1.13)\end{array}$ & $\begin{array}{c}-3.20^{* * * *} \\
(.88)\end{array}$ \\
\hline Year Before Super Bowl & $\begin{array}{c}.00004 \\
(.0007)\end{array}$ & $\begin{array}{c}.0006 \\
(.0004)\end{array}$ & $\begin{array}{c}.0006 \\
(.0005)\end{array}$ & $\begin{array}{c}2.78 \\
(4.29)\end{array}$ & $\begin{array}{r}-1.44 \\
(.93)\end{array}$ & $\begin{array}{l}-1.12 \\
(1.37)\end{array}$ \\
\hline Year After Super Bowl & $\begin{array}{c}.0003 \\
(.0006)\end{array}$ & $\begin{array}{c}.0007 \\
(.0006)\end{array}$ & $\begin{array}{c}.0005 \\
(.0004)\end{array}$ & $\begin{array}{c}1.34 \\
(2.73)\end{array}$ & $\begin{array}{l}-1.82 \\
(1.61)\end{array}$ & $\begin{array}{l}-1.10 \\
(1.22)\end{array}$ \\
\hline NFL Area \& Year Fixed Effects & Yes & Yes & Yes & Yes & Yes & Yes \\
\hline Area-Specific Linear Trends & No & Yes & Yes & No & Yes & Yes \\
\hline Controls & No & No & Yes & No & No & Yes \\
\hline Sample Size & $12,179,714$ & $12,179,714$ & $12,179,714$ & $12,179,714$ & $12,179,714$ & $12,179,714$ \\
\hline
\end{tabular}

${ }^{*}$ Statistically significant at $10 \%$ level; ${ }^{* *}$ at $5 \%$ level; ${ }^{* * *}$ at $1 \%$ level.

Notes: Standard errors clustered at the NFL fan base level are shown in parentheses. Not reaching the divisional playoffs (the reference category), losing in the divisional playoff, losing in the conference playoff, and going to the Super Bowl are mutually exclusive and exhaustive events. Where indicated, regressions include year fixed effects, area fixed effects, and area-specific linear time trends. Controls include indicators for month of conception, sex of the child, hospital birth, multiple birth, mother's first birth, father indicated on birth certificate, mother's race, ethnicity, education, age, and marital status. 
Table 4. The relationship between birth weight and Super Bowl wins and losses

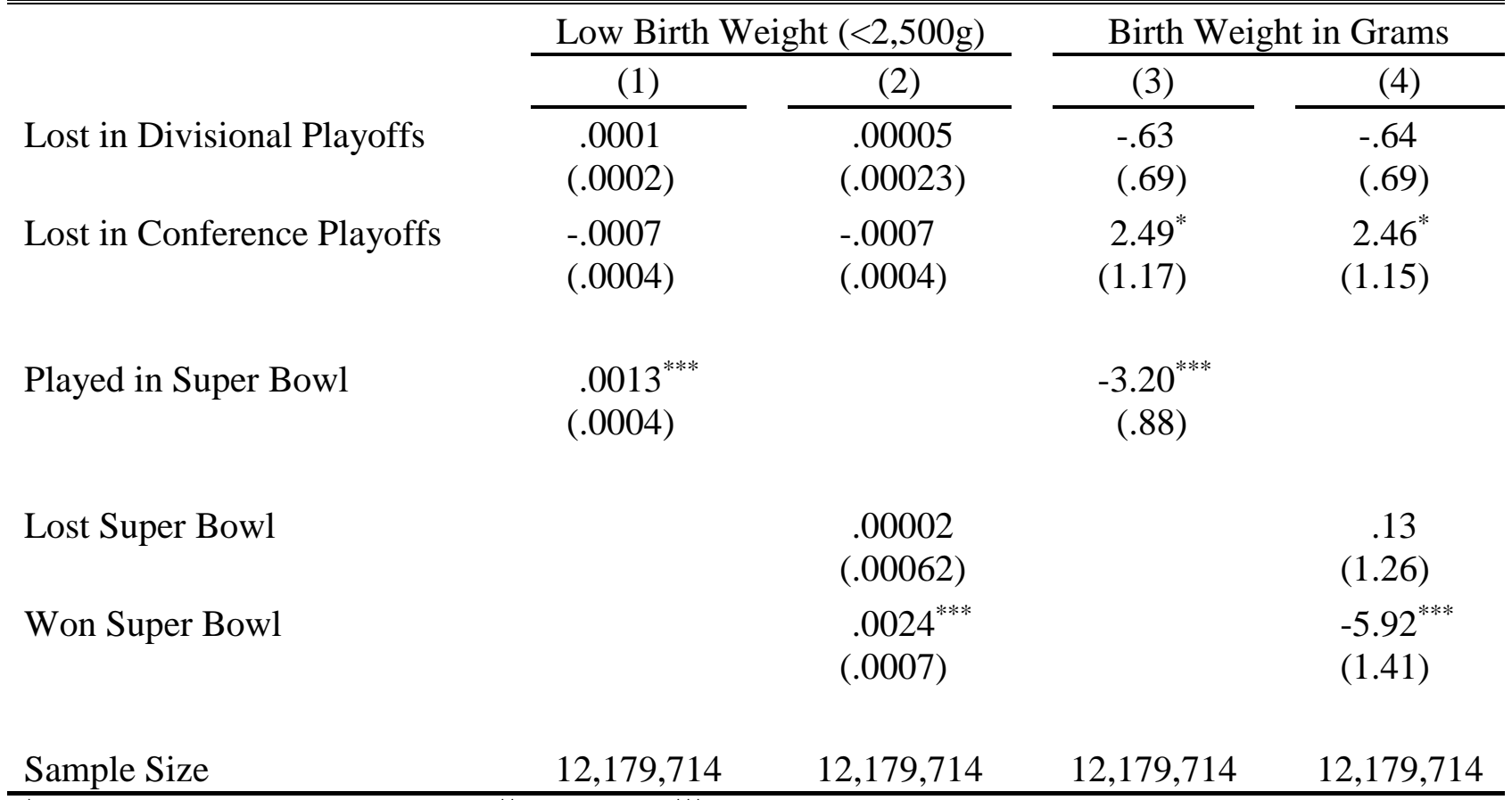

${ }^{*}$ Statistically significant at $10 \%$ level; ${ }^{* *}$ at $5 \%$ level; ${ }^{* * *}$ at $1 \%$ level.

Notes: Standard errors clustered at the NFL fan base level are shown in parentheses. Not reaching the divisional playoffs (the reference category), losing in the divisional playoff, losing in the conference playoff, and going to the Super Bowl are mutually exclusive and exhaustive events. All regressions include year fixed effects, area fixed effects, and area-specific linear time trends. In addition, they include indicators for the year before and year after a Super Bowl, month of conception, sex of the child, hospital birth, multiple birth, mother's first birth, father indicated on birth certificate, mother's race, ethnicity, education, age, and marital status. 
Table 5. The relationship between the Super Bowl and low birth weight by mother's characteristic

\begin{tabular}{|c|c|c|c|c|c|c|}
\hline \multirow{2}{*}{$\begin{array}{l}\text { Panel A } \\
\text { Played in Super Bowl }\end{array}$} & \multicolumn{2}{|c|}{ No High School Degree } & \multicolumn{2}{|c|}{ High School } & \multicolumn{2}{|c|}{ College } \\
\hline & $\begin{array}{l}.0019^{* *} \\
(.0008)\end{array}$ & & $\begin{array}{l}.0007 \\
(.0005)\end{array}$ & & $\begin{array}{l}.0007 \\
(.0007)\end{array}$ & \\
\hline Lost Super Bowl & & $\begin{array}{l}-.0019 \\
(.0017)\end{array}$ & & $\begin{array}{l}-.0002 \\
(.0007)\end{array}$ & & $\begin{array}{l}.0009 \\
(.0013)\end{array}$ \\
\hline Won Super Bowl & & $\begin{array}{l}.0047^{* * *} \\
(.0008)\end{array}$ & & $\begin{array}{c}.0014 \\
(.0011)\end{array}$ & & $\begin{array}{l}.0005 \\
(.0007)\end{array}$ \\
\hline Sample Size & $2,519,958$ & $2,519,958$ & $5,550,522$ & $5,550,522$ & $2,088,446$ & $2,088,446$ \\
\hline Panel B & & & & & & \\
\hline Played in Super Bowl & $\begin{array}{l}.0007^{* *} \\
(.0003)\end{array}$ & & $\begin{array}{l}.0036^{* * * *} \\
(.0011)\end{array}$ & & $\begin{array}{l}.0034^{* * *} \\
(.0010)\end{array}$ & \\
\hline Lost Super Bowl & & $\begin{array}{l}-.0004 \\
(.0006)\end{array}$ & & $\begin{array}{l}.0010 \\
(.0019)\end{array}$ & & $\begin{array}{l}.0019 \\
(.0016)\end{array}$ \\
\hline Won Super Bowl & & $\begin{array}{l}.0017^{* * * *} \\
(.0005)\end{array}$ & & $\begin{array}{l}.0054^{* * *} \\
(.0009)\end{array}$ & & $\begin{array}{l}.0045^{* * *} \\
(.0012)\end{array}$ \\
\hline Sample Size & $9,163,341$ & $9,163,341$ & $2,382,340$ & $2,382,340$ & $2,359,590$ & $2,359,590$ \\
\hline Panel C & & & & & & \\
\hline Played in Super Bowl & $\begin{array}{l}.0007^{* *} \\
(.0003)\end{array}$ & & $\begin{array}{l}.0034^{* * *} \\
(.0009)\end{array}$ & & & \\
\hline Lost Super Bowl & & $\begin{array}{c}.0001 \\
(.0006)\end{array}$ & & $\begin{array}{l}.0004 \\
(.0014)\end{array}$ & & \\
\hline Won Super Bowl & & $\begin{array}{l}.0011^{* *} \\
(.0004)\end{array}$ & & $\begin{array}{l}.0058^{* * *} \\
(.0009)\end{array}$ & & \\
\hline Sample Size & $7,784,343$ & $7,784,343$ & $3,329,771$ & $3,329,771$ & & \\
\hline
\end{tabular}

${ }^{*}$ Statistically significant at $10 \%$ level; ${ }^{* *}$ at $5 \%$ level; ${ }^{* * *}$ at $1 \%$ level.

Notes: Standard errors clustered at the NFL fan base level are shown in parentheses. Not reaching the divisional playoffs (the reference category), losing in the divisional playoff, losing in the conference playoff, and going to the Super Bowl are mutually exclusive and exhaustive events. All regressions include year fixed effects, area fixed effects, and area-specific linear time trends. In addition, they include indicators for the year before and year after a Super Bowl, month of conception, sex of the child, hospital birth, multiple birth, mother's first birth, father indicated on birth certificate, mother's race, ethnicity, age, and marital status. 
Table 6. The relationship between low birth weight and Super Bowl exposure

\begin{tabular}{|c|c|c|c|}
\hline & (1) & (2) & (3) \\
\hline Lost in Divisional Playoffs & $\begin{array}{c}.0001 \\
(.0002)\end{array}$ & $\begin{array}{l}-.00005 \\
(.00023)\end{array}$ & $\begin{array}{c}.00005 \\
(.00023)\end{array}$ \\
\hline Lost in Conference Playoffs & $\begin{array}{l}-.0005 \\
(.0006)\end{array}$ & $\begin{array}{l}-.0007 \\
(.0004)\end{array}$ & $\begin{array}{l}-.0007^{*} \\
(.0004)\end{array}$ \\
\hline Played in Super Bowl & $\begin{array}{l}.0013^{* * *} \\
(.0004)\end{array}$ & & \\
\hline Lost Super Bowl & & $\begin{array}{l}-.00002 \\
(.00062)\end{array}$ & \\
\hline Upset Loss & & & $\begin{array}{c}.0001 \\
(.0012)\end{array}$ \\
\hline Unpredictable Loss & & & $\begin{array}{l}.0003 \\
(.0011)\end{array}$ \\
\hline Predicted Loss & & & $\begin{array}{l}-.0002 \\
(.0008)\end{array}$ \\
\hline Won Super Bowl & & $\begin{array}{l}.0024^{* * *} \\
(.0007)\end{array}$ & \\
\hline Upset Win & & & $\begin{array}{l}.0047^{* * *} \\
(.0004)\end{array}$ \\
\hline Unpredictable Win & & & $\begin{array}{c}.00001 \\
(.00183)\end{array}$ \\
\hline Predicted Win & & & $\begin{array}{l}.0023^{* * * *} \\
(.0005)\end{array}$ \\
\hline Sample Size & $12,179,714$ & $12,179,714$ & $12,179,714$ \\
\hline
\end{tabular}

"Statistically significant at $10 \%$ level; ${ }^{* *}$ at $5 \%$ level; ${ }^{* * *}$ at $1 \%$ level.

Notes: Standard errors clustered at the NFL fan base level are shown in parentheses. Not reaching the divisional playoffs (the reference category), losing in the divisional playoff, losing in the conference playoff, and going to the Super Bowl are mutually exclusive and exhaustive events. An upset/predicted win/loss occurred when the Las Vegas point spread was greater than or equal to four points. An unpredictable win/loss occurred when the Las Vegas point spread was less than four points. All regressions include year fixed effects, area fixed effects, and areaspecific linear time trends. In addition, they include indicators for the year before and year after a Super Bowl, month of conception, sex of the child, hospital birth, multiple birth, mother's first birth, father indicated on birth certificate, mother's race, ethnicity, education, age, and marital status. 
Table 7. The relationship between birth weight and Super Bowl exposure, controlling for gestation

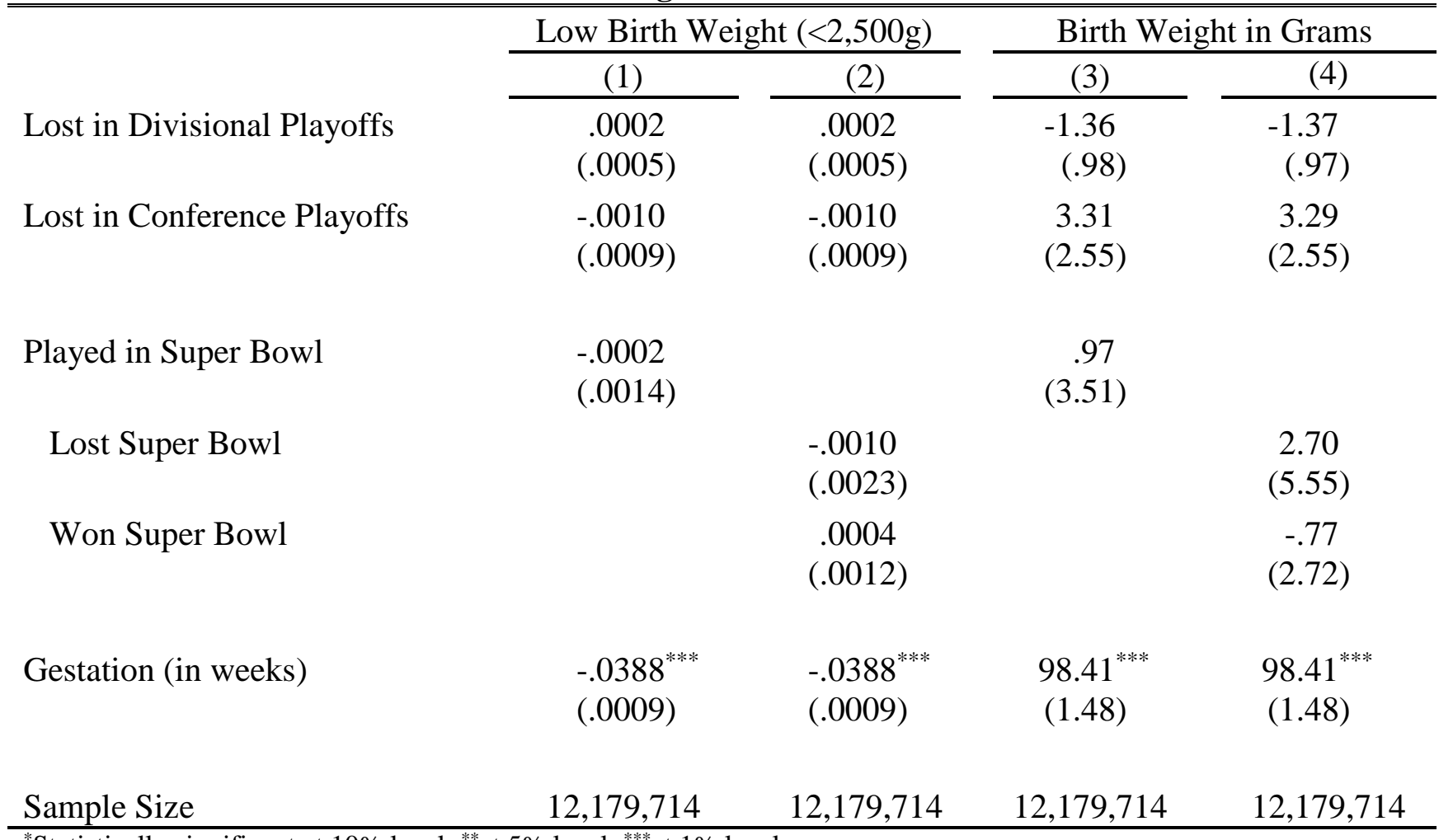

${ }^{*}$ Statistically significant at $10 \%$ level; ${ }^{* *}$ at $5 \%$ level; ${ }^{* * *}$ at $1 \%$ level.

Notes: Standard errors clustered at the NFL fan base level are shown in parentheses. Not reaching the divisional playoffs (the reference category), losing in the divisional playoff, losing in the conference playoff, and going to the Super Bowl are mutually exclusive and exhaustive events. All regressions include year fixed effects, area fixed effects, and area-specific linear time trends. In addition, they include indicators for the year before and year after a Super Bowl, month of conception, sex of the child, hospital birth, multiple birth, mother's first birth, father indicated on birth certificate, mother's race, ethnicity, education, age, and marital status. 
Table 8. The relationship between the Super Bowl and low birth weight by likely month of conception

\section{Panel A}

Played in Super Bowl

\section{Panel B}

Lost Super Bowl

Won Super Bowl

\begin{tabular}{|c|c|c|c|c|c|}
\hline July & August & September & October & November & December \\
\hline $\begin{array}{l}.0004 \\
(.0004)\end{array}$ & $\begin{array}{c}.0006 \\
(.0006)\end{array}$ & $\begin{array}{l}.0008 \\
(.0007)\end{array}$ & $\begin{array}{c}.0005 \\
(.0007)\end{array}$ & $\begin{array}{c}.0013^{*} \\
(.0007)\end{array}$ & $\begin{array}{l}.0023^{\text {**** }} \\
(.0005)\end{array}$ \\
\hline
\end{tabular}

\begin{tabular}{|c|c|c|c|c|c|}
\hline July & August & September & October & November & December \\
\hline $\begin{array}{l}-.0007 \\
(.0008)\end{array}$ & $\begin{array}{l}-.0001 \\
(.0009)\end{array}$ & $\begin{array}{l}.0005 \\
(.0008)\end{array}$ & $\begin{array}{l}-.0010 \\
(.0010)\end{array}$ & $\begin{array}{l}.0011 \\
(.0007)\end{array}$ & $\begin{array}{c}.0022^{*} \\
(.0012)\end{array}$ \\
\hline $\begin{array}{l}.0013^{* *} \\
(.0005)\end{array}$ & $\begin{array}{l}.0012^{* * *} \\
(.0006)\end{array}$ & $\begin{array}{l}.0019^{* *} \\
(.0009)\end{array}$ & $\begin{array}{c}.0018^{*} \\
(.0010)\end{array}$ & $\begin{array}{l}.0032^{* * * *} \\
(.0008)\end{array}$ & $\begin{array}{l}.0023^{* * * *} \\
(.0006)\end{array}$ \\
\hline
\end{tabular}

${ }^{*}$ Statistically significant at $10 \%$ level; ${ }^{* *}$ at $5 \%$ level; ${ }^{* * *}$ at $1 \%$ level.

Notes: Standard errors clustered at the NFL fan base level are shown in parentheses. All regressions include year fixed effects, area fixed effects, and area-specific linear time trends. In addition, they include indicators for the year before and year after a Super Bowl, month of conception, sex of the child, hospital birth, multiple birth, mother's first birth, father indicated on birth certificate, mother's race, ethnicity, education, age, and marital status. 
Table 9. The relationship between tobacco use during pregnancy and Super Bowl exposure. Analysis restricted to the years 1989-2004.

\begin{tabular}{|c|c|c|c|}
\hline & (1) & (2) & (3) \\
\hline Lost in Divisional Playoffs & $\begin{array}{l}-.0013^{*} \\
(.0008)\end{array}$ & $\begin{array}{l}-.0013^{*} \\
(.0007)\end{array}$ & $\begin{array}{l}-.0013^{*} \\
(.0007)\end{array}$ \\
\hline Lost in Conference Playoffs & $\begin{array}{c}.0012 \\
(.0018)\end{array}$ & $\begin{array}{c}.0011 \\
(.0018)\end{array}$ & $\begin{array}{c}.0011 \\
(.0018)\end{array}$ \\
\hline Played in Super Bowl & $\begin{array}{c}.0027^{*} \\
(.0014)\end{array}$ & & \\
\hline Lost Super Bowl & & $\begin{array}{l}-.0006 \\
(.0023)\end{array}$ & \\
\hline Upset Loss & & & $\begin{array}{c}.0102 \\
.0062)\end{array}$ \\
\hline Unpredictable Loss & & & $\begin{array}{l}-.0013 \\
(.0009)\end{array}$ \\
\hline Predicted Loss & & & $\begin{array}{l}-.0015 \\
(.0038)\end{array}$ \\
\hline Won Super Bowl & & $\begin{array}{c}.0055^{* *} \\
(.0027)\end{array}$ & \\
\hline Upset Win & & & $\begin{array}{c}.0038 \\
(.0031)\end{array}$ \\
\hline Unpredictable Win & & & $\begin{array}{c}.0001 \\
(.0010)\end{array}$ \\
\hline Predicted Win & & & $\begin{array}{c}.0069^{*} \\
(.0036)\end{array}$ \\
\hline Sample Size & $4,343,232$ & $4,343,232$ & $4,343,232$ \\
\hline
\end{tabular}

"Statistically significant at $10 \%$ level; ${ }^{* *}$ at $5 \%$ level; ${ }^{* * *}$ at $1 \%$ level.

Notes: Standard errors clustered at the NFL fan base level are shown in parentheses. Not reaching the divisional playoffs (the reference category), losing in the divisional playoff, losing in the conference playoff, and going to the Super Bowl are mutually exclusive and exhaustive events. An upset/predicted win/loss occurred when the Las Vegas point spread was greater than or equal to four points. An unpredictable win/loss occurred when the Las Vegas point spread was less than four points. All regressions include year fixed effects, area fixed effects, and areaspecific linear time trends. In addition, they include indicators for the year before and year after a Super Bowl, month of conception, sex of the child, mother's first birth, mother's race, ethnicity, education, age, and marital status. 
Appendix Table 1. Super Bowl outcomes, 1969-2004

\begin{tabular}{|c|c|c|c|c|}
\hline Super Bowl & Date & Winning Team & Losing Team & Winner's Line \\
\hline XXXVIII & $2 / 1 / 2004$ & New England Patriots 32 & Carolina Panthers 29 & $-7(\mathrm{P})$ \\
\hline XXXVII & $1 / 26 / 2003$ & Tampa Bay Buccaneers 48 & Oakland Raiders 21 & $+4(\mathrm{U})$ \\
\hline XXXVI & $2 / 3 / 2002$ & New England Patriots 20 & St. Louis Rams 17 & $+14(\mathrm{U})$ \\
\hline XXXV & $1 / 28 / 2001$ & Baltimore Ravens 34 & New York Giants 7 & -3 \\
\hline XXXIV & $1 / 30 / 2000$ & St. Louis Rams 23 & Tennessee Titans 16 & $-7(\mathrm{P})$ \\
\hline XXXIII & $1 / 31 / 1999$ & Denver Broncos 34 & Atlanta Falcons 19 & $-71 / 2(\mathrm{P})$ \\
\hline XXXII & $1 / 25 / 1998$ & Denver Broncos 31 & Green Bay Packers 24 & $+11(\mathrm{U})$ \\
\hline XXXI & $1 / 26 / 1997$ & Green Bay Packers 35 & New England Patriots 21 & $-14(\mathrm{P})$ \\
\hline XXX & $1 / 28 / 1996$ & Dallas Cowboys 27 & Pittsburgh Steelers 17 & $-131 / 2(\mathrm{P})$ \\
\hline XXIX & $1 / 29 / 1995$ & San Francisco 49ers 49 & San Diego Chargers 26 & $-181 / 2(\mathrm{P})$ \\
\hline XXVIII & $1 / 30 / 1994$ & Dallas Cowboys 30 & Buffalo Bills 13 & $-101 / 2(\mathrm{P})$ \\
\hline XXVII & $1 / 31 / 1993$ & Dallas Cowboys 52 & Buffalo Bills 17 & $-61 / 2(P)$ \\
\hline XXVI & $1 / 26 / 1992$ & Washington Redskins 37 & Buffalo Bills 24 & $-7(\mathrm{P})$ \\
\hline XXV & $1 / 27 / 1991$ & New York Giants 20 & Buffalo Bills 19 & $+7(\mathrm{U})$ \\
\hline XXIV & $1 / 28 / 1990$ & San Francisco 49ers 55 & Denver Broncos 10 & $-12(\mathrm{P})$ \\
\hline XXIII & $1 / 22 / 1989$ & San Francisco 49ers 20 & Cincinnati Bengals 16 & $-7(\mathrm{P})$ \\
\hline XXII & $1 / 31 / 1988$ & Washington Redskins 42 & Denver Broncos 10 & +3 \\
\hline XXI & $1 / 25 / 1987$ & New York Giants 39 & Denver Broncos 20 & $-91 / 2(\mathrm{P})$ \\
\hline $\mathrm{XX}$ & $1 / 26 / 1986$ & Chicago Bears 46 & New England Patriots 10 & $-10(\mathrm{P})$ \\
\hline XIX & $1 / 20 / 1985$ & San Francisco 49ers 38 & Miami Dolphins 16 & $-31 / 2$ \\
\hline XVIII & $1 / 22 / 1984$ & LA Raiders 38 & Washington Redskins 9 & +3 \\
\hline XVII & $1 / 30 / 1983$ & Washington Redskins 27 & Miami Dolphins 17 & +3 \\
\hline XVI & $1 / 24 / 1982$ & San Francisco 49ers 26 & Cincinnati Bengals 21 & -1 \\
\hline XV & $1 / 25 / 1981$ & Oakland Raiders 27 & Philadelphia Eagles 10 & +3 \\
\hline XIV & $1 / 20 / 1980$ & Pittsburgh Steelers 31 & Los Angeles Rams 19 & $-10^{1 / 2}(\mathrm{P})$ \\
\hline XIII & $1 / 21 / 1979$ & Pittsburgh Steelers 35 & Dallas Cowboys 31 & $-31 / 2$ \\
\hline XII & $1 / 15 / 1978$ & Dallas Cowboys 27 & Denver Broncos 10 & $-6(P)$ \\
\hline XI & $1 / 9 / 1977$ & Oakland Raiders 32 & Minnesota Vikings 14 & $-4(\mathrm{P})$ \\
\hline $\mathrm{X}$ & $1 / 18 / 1976$ & Pittsburgh Steelers 21 & Dallas Cowboys 17 & $-7(\mathrm{P})$ \\
\hline IX & $1 / 12 / 1975$ & Pittsburgh Steelers 16 & Minnesota Vikings 6 & -3 \\
\hline VIII & $1 / 13 / 1974$ & Miami Dolphins 24 & Minnesota Vikings 7 & $-61 / 2(P)$ \\
\hline VII & $1 / 14 / 1973$ & Miami Dolphins 14 & Washington Redskins 7 & -1 \\
\hline VI & $1 / 16 / 1972$ & Dallas Cowboys 24 & Miami Dolphins 3 & $-6(P)$ \\
\hline $\mathrm{V}$ & $1 / 17 / 1971$ & Baltimore Colts 16 & Dallas Cowboys 13 & $-2 \frac{1}{2}$ \\
\hline IV & $1 / 11 / 1970$ & Kansas City Chiefs 23 & Minnesota Vikings 7 & $+12(\mathrm{U})$ \\
\hline III & $1 / 12 / 1969$ & New York Jets 16 & Baltimore Colts 7 & $+18(\mathrm{U})$ \\
\hline
\end{tabular}

Notes: The winner's line, also known as the point spread, is the predicted margin of victory (it is actually the predicted margin of victory odds makers believe will elicit an equal amount of betting on both teams). A negative line indicates that the team is a favorite, whereas a positive line indicates the team is an underdog (e.g. a positive number in the winner's line column indicates that the underdog team won the super bowl). A predicted outcome (P) occurs when the winner's line is less than or equal to -4 . An upset $(\mathrm{U})$ occurs when the winner's line is greater than or equal to +4 . The outcomes of games with a point spread between -4 and +4 are considered unpredictable. 
Appendix Table 2. Descriptive statistics, by Super Bowl exposure

\begin{tabular}{|c|c|c|c|}
\hline \multirow[b]{2}{*}{ Birth outcomes } & \multirow{2}{*}{$\begin{array}{c}\text { Not in Divisional } \\
\text { Playoffs }\end{array}$} & \multicolumn{2}{|c|}{ Played in Super Bowl } \\
\hline & & Lost & Won \\
\hline Birth weight (in grams) & $\begin{array}{c}3,314.3 \\
(.2)\end{array}$ & $\begin{array}{c}3,312.2 \\
(1.0)\end{array}$ & $\begin{array}{c}3,292.6 \\
(1.0)\end{array}$ \\
\hline Low birth weight $(<2,500 \mathrm{~g})$ & .0736 & .0737 & .0784 \\
\hline Gestation length (in weeks) & $\begin{array}{l}39.0 \\
(.001)\end{array}$ & $\begin{array}{l}38.9 \\
(.004)\end{array}$ & $\begin{array}{l}38.9 \\
(.004)\end{array}$ \\
\hline Preterm birth (<35 weeks gestation) & .0974 & .0868 & .0963 \\
\hline Multiple birth & .0244 & .0250 & .0240 \\
\hline Born in hospital & .9880 & .9860 & .9900 \\
\hline Father indicated on birth certificate & .8826 & .8930 & .8896 \\
\hline \multicolumn{4}{|l|}{ Mother's characteristics } \\
\hline Age & $\begin{array}{l}26.6 \\
(.002)\end{array}$ & $\begin{array}{c}26.7 \\
(.011)\end{array}$ & $\begin{array}{c}26.8 \\
(.010)\end{array}$ \\
\hline Married & .6477 & .6824 & .6335 \\
\hline Unknown marital status & .0756 & .0549 & .1085 \\
\hline First born child & .4078 & .4224 & .4291 \\
\hline White & .7540 & .7609 & .7250 \\
\hline Black & .1948 & .1878 & .2131 \\
\hline Asian & .0439 & .0435 & .0534 \\
\hline Other Race & .0073 & .0078 & .0084 \\
\hline Hispanic & .1935 & .1661 & .1860 \\
\hline Unknown Hispanic origin & .2610 & .2920 & .2486 \\
\hline Less than four high school & .2140 & .1579 & .1924 \\
\hline Four years of high school or some college & .4675 & .4479 & .4247 \\
\hline Four or more years of college & .1740 & .1869 & .1809 \\
\hline Education not reported & .1445 & .2073 & .2019 \\
\hline Alcohol use & .0161 & .0127 & .0148 \\
\hline Drinks per week (conditional on alcohol use) & $\begin{array}{c}2.8 \\
(.03)\end{array}$ & $\begin{array}{c}2.3 \\
(.12)\end{array}$ & $\begin{array}{l}2.5 \\
(.09)\end{array}$ \\
\hline Tobacco use & .1110 & .0872 & .0815 \\
\hline Cigarettes per day (conditional on tobacco use) & $\begin{array}{l}11.1 \\
(.01)\end{array}$ & $\begin{array}{l}1.7 \\
(.08)\end{array}$ & $\begin{array}{l}1.1 \\
(.07)\end{array}$ \\
\hline Sample Size & $8,966,017$ & 313,773 & 389,471 \\
\hline
\end{tabular}

Source: National Center for Health Statistics, Vital Statistics Data, 1969-2004.

Notes: Standard errors for continuous variables are shown in parentheses. The sample includes children who were conceived by mothers living in an NFL fan base area in October, November, or December. Month of conception was assigned using gestation duration (in weeks) and month of birth. NFL fan base area was assigned using the mother's county of residence. If an NFL stadium was located in a county at any time during the period 1969 through 2004, then that county and its neighboring counties constitute an NFL fan base area. Hispanic origin questions first appear in the Vital Statistics Data in 1978; substance use questions first appear in in 1988. 


\section{Appendix Table 3. The relationship between alcohol use during pregnancy}

and Super Bowl exposure. Analysis restricted to the years 1989-2004.

\begin{tabular}{|c|c|c|c|}
\hline & $(1)$ & (2) & $(3)$ \\
\hline Lost in Divisional Playoffs & $\begin{array}{l}-.0004 \\
(.0005)\end{array}$ & $\begin{array}{l}-.0004 \\
(.0005)\end{array}$ & $\begin{array}{l}-.0004 \\
(.0005)\end{array}$ \\
\hline Lost in Conference Playoffs & $\begin{array}{l}-.0010 \\
(.0009)\end{array}$ & $\begin{array}{l}-.0010 \\
(.0009)\end{array}$ & $\begin{array}{l}-.0010 \\
(.0009)\end{array}$ \\
\hline Played in Super Bowl & $\begin{array}{c}.0019 \\
(.0012)\end{array}$ & & \\
\hline Lost Super Bowl & & $\begin{array}{l}-.0018 \\
(.0016)\end{array}$ & \\
\hline Upset Loss & & & $\begin{array}{c}.0024 \\
(.0024)\end{array}$ \\
\hline Unpredictable Loss & & & $\begin{array}{l}-.0006 \\
(.0005)\end{array}$ \\
\hline Predicted Loss & & & $\begin{array}{l}-.0029 \\
(.0026)\end{array}$ \\
\hline Won Super Bowl & & $\begin{array}{l}.0053^{* *} \\
(.0026)\end{array}$ & \\
\hline Upset Win & & & $\begin{array}{c}.0049 \\
(.0031)\end{array}$ \\
\hline Unpredictable Win & & & $\begin{array}{l}.0015^{\text {*** }} \\
(.0005)\end{array}$ \\
\hline Predicted Win & & & $\begin{array}{c}.0058^{*} \\
(.0029)\end{array}$ \\
\hline Sample Size & $4,436,824$ & $4,436,824$ & $4,436,824$ \\
\hline \multicolumn{4}{|c|}{${ }^{*}$ Statistically significant at $10 \%$ level $;{ }^{* *}$ at $5 \%$ level; ${ }^{* * * *}$ at $1 \%$ level. } \\
\hline \multicolumn{4}{|c|}{$\begin{array}{l}\text { Notes: Standard errors clustered at the NFL fan base level are shown in parentheses. Not } \\
\text { reaching the divisional playoffs (the reference category), losing in the divisional playoff, losing } \\
\text { in the conference playoff, and going to the Super Bowl are mutually exclusive and exhaustive } \\
\text { events. An upset/predicted win/loss occurred when the Las Vegas point spread was greater than } \\
\text { or equal to four points. An unpredictable win/loss occurred when the Las Vegas point spread } \\
\text { was less than four points. All regressions include year fixed effects, area fixed effects, and area- } \\
\text { specific linear time trends. In addition, they include indicators for the year before and year after } \\
\text { a Super Bowl, month of conception, sex of the child, mother's first birth, mother's race, } \\
\text { ethnicity, education, age, and marital status. }\end{array}$} \\
\hline
\end{tabular}

